\title{
Advancing behavioral interventions for African American/Black and Latino persons living with HIV by integrating critical race theory, harm reduction, and self-determination theory: A qualitative exploratory study
}

Marya Gwadz ( $\square$ mg2890@nyu.edu )

New York University https://orcid.org/0000-0002-2386-9409

\section{Research Article}

Keywords: qualitative, critical race theory, harm reduction, self-determination theory, HIV survivorship research, HIV care continuum, structural racism, racial/ethnic disparities, structural competency, cultural competency

Posted Date: February 10th, 2022

DOI: https://doi.org/10.21203/rs.3.rs-1344207/v1

License: (c) (1) This work is licensed under a Creative Commons Attribution 4.0 International License. Read Full License 


\section{Abstract \\ Background}

. Rates of participation in HIV care, medication uptake, and viral suppression are improving among persons living with HIV (PLWH) in the United States. Yet, racial/ethnic disparities in engagement along this HIV care continuum are persistent, particularly among African American/Black and Latino PLWH, signaling the need for novel approaches. We created a new conceptual model that integrates critical race theory, harm reduction, and self-determination theory, which was used to plan an intervention optimization trial to test five behavioral intervention comcompponents. The present qualitative exploratory study describes the integrated conceptual model (ICM) and explores participants' perspectives on contributions of the ICM to study acceptability, feasibility, and impact.

\section{Methods}

. Participants were African American/Black and Latino PLWH poorly engaged in HIV care and with nonsuppressed HIV viral load in New York City. From the parent optimization trial $(N=512)$, we randomly selected 46 for in-depth semi-structured interviews on experiences in the optimization trial. Interviews were audio-recorded and professionally transcribed verbatim, and data were analyzed using directed qualitative content analysis.

\section{Results}

. On average, participants were 49 years old $(S D=9)$ and had lived with HIV for 19 years $(S D=7)$. Most were male (78\%) and African American/Black (76\%). All had taken HIV medication previously. Challenging life contexts were the norm comprised of poverty, poor quality/unstable housing, trauma histories exacerbated by current trauma, medical and mental health comorbidities, and substance use. Participants found the optimization trial highly acceptable. We organized results into four themes focused on the importance of 1 ) being understood as a whole person and in context; 2 ) trustworthiness and trust; 3 ) opportunities for self-reflection; and 4) support of personal autonomy. The salience of nonjudgment was prominent in each theme. Their experiences and perspectives reflected the ICM. Participants reported these characteristics were generally lacking in HIV care settings.

\section{Conclusions}

. The ICM for is a new useful model for research with AABL-PLWH with potential to enhance study acceptability, feasibility, and intervention effectiveness. Future application of the ICM is warranted to reduce racial/ethnic disparities. In a future study, we will explore participants' perspectives on the specific intervention components in which they engaged and ways components can be improved. 


\section{Background}

The HIV care continuum is a public health model outlining the steps recommended for persons living with HIV (PLWH) to achieve optimal health and wellbeing and ultimately end the HIV epidemic [1]. This care continuum begins with HIV diagnosis, followed by linkage to HIV primary care, engagement and retention in care, and uptake of HIV antiretroviral therapy with high levels of adherence to achieve and sustain HIV viral suppression [1]. Rates of engagement along the HIV care continuum have improved among PLWH as a whole in the United States in the past decade [2]. Yet, a substantial proportion of PLWH, mainly those from African American/Black and Latino (AABL) racial/ethnic backgrounds, are poorly engaged or inconsistently engaged and, in fact, often do not sustain HIV viral suppression [2]. These racial and ethnic disparities along the HIV care continuum are marked and persistent. First, AABL persons are greatly overrepresented in the population of PLWH compared to their proportions in the underlying general population [2]. Current national data indicate that while $67 \%$ of White PLWH receive HIV primary care, only $58-59 \%$ of AABL-PLWH do so, and while $57 \%$ of White PLWH are HIV virally suppressed, only $48 \%$ of Latino and $43 \%$ of African American/Black PLWH achieve this important health indicator [2]. Of further concern, rates of sustained HIV viral suppression are lowest among African American/Black PLWH: an estimated $41 \%$ sustain viral suppression, compared to $50 \%$ among Latino and $56 \%$ among White PLWH [3]. Long periods of non-suppressed HIV viral load have potential serious adverse effects on health; they can damage immune system functioning and reduce quality of life [4]. Moreover, those with nonsuppressed HIV viral load have elevated chances of forward transmission of HIV to others compared to those with sustained viral suppression [5].

There is a growing consensus that while public health research commonly focuses on race (e.g., differences between racial groups), it does not adequately attend to issues of racism, including structural racism [6]. Other recent work highlights that social and behavioral interventions to improve engagement along the care continuum for AABL-PLWH show insufficient cultural competence [7] . Leaders in U.S. public health have set a goal of ending the HIV epidemic by 2030 [8] . This will entail $95 \%$ of those living with HIV being diagnosed, $95 \%$ of those diagnosed receiving HIV medication, and $95 \%$ of all people receiving medication achieving HIV viral suppression, called 95-95-95 goals [9]. However, this goal will not be achieved without reducing or eliminating racial/ethnic disparities along the HIV care continuum [10]. In the sections that follow we review the factors that cause these racial/ethnic disparities among AABL$\mathrm{PLWH}$, then briefly summarize the theories and approaches that comprise ICM; namely, critical race theory, harm reduction, and self-determination theory, followed by the rationale for the integrated conceptual model (ICM) that is the focus of the present study.

\section{Multi-level factors cause poor engagement along the HIV care continuum}


The reasons AABL-PLWH are poorly engaged along the HIV care continuum are complex and operate at multiple levels of influence. These barriers can be organized using the theory of triadic influence, which articulates structural-, social-, and individual/attitudinal-level streams of influence on health behavior [11]. Structural-level barriers for this population encompass aspects of systemic and institutionalized racism, a form of racism embedded through laws and regulations within society or organizations [12]. Examples of systemic racism for AABL-PLWH include factors that also affect AABL populations as a whole and include disproportional targeting by criminal justice entities, poor-quality health care settings in the neighborhoods where AABL populations are concentrated, financial benefit levels that keep people in chronic poverty, and unstable and/or low-quality housing and homelessness [13]. Other examples include pervasive surveillance mechanisms that commonly monitor AABL-PLWH, such as probation, parole, and supervised supportive housing, which undermine dignity, autonomy, and self-determination [14]. Chronic poverty creates competing priorities related to survival needs such as food insecurity and also makes AABL-PLWH vulnerable to "diversion" of HIV medication; that is, the selling of HIV medication to pharmacies who solicit and compensate PLWH for prescriptions, although it is illegal for pharmacies to do so [15]. Aspects of the United States health care system can impede engagement along the HIV care continuum. AABL-PLWH on the whole express satisfaction with their health care providers, but evidence dissatisfaction with the health care and social service system and care settings [16]. Moreover, substance use at both non-hazardous and hazardous levels, past and present, are common among AABL-PLWH [17] but treatment for hazardous substance use among AABLPLWH has historically been influenced by the abstinence-only model, and by punitive approaches that are not generally acceptable to or effective for AABL-PLWH [18].

Social-level barriers to engagement along the HIV care continuum for this population include complex stigma [19]. AABL-PLWH experience stigma related to HIV, certainly, as well as to sociodemographic characteristics such as race/ethnicity, social class, and sexual/gender minority status, and also from a wide range of sources including institutional settings [20,21]. Stigma in health care and social service settings related to substance use impedes access to appropriate substance use treatment and medical care $[20,22]$. Stigma further contributes to AABL-PLWH experiencing a general lack of social support from family and peers, and to extreme social isolation, all of which impede engagement along the HIV care continuum [23].

At the individual/attitudinal level of influence, primary barriers to engagement along the HIV care continuum include fear and distrust of HIV medications, of the health care system and medical settings, and to a lesser extent, of providers [24]. Counter-narratives about the causes and treatments of HIV (called conspiracy theories in some cases) are another aspect of distrust [24, 25]. Other barriers include substance use and mental health concerns [26-29]. Motivation to take HIV medication varies over time, but even when AABL-PLWH are ready to initiate HIV medication with high levels of adherence, motivation 
alone is commonly insufficient to overcome these multi-level barriers [30]. Yet despite these impediments, AABL-PLWH certainly do evidence substantial periods where they overcome obstacles and engage along the HIV care continuum [27]. Yet, taken together, these barriers clearly serve as serious impediments to HIV management in this population. The present qualitative exploratory study focuses on AABL-PLWH with socioeconomic disadvantage who are not engaged in HIV care at recommended levels and who do not evidence HIV viral suppression, a population that is under-studied compared to those well engaged in HIV care [31-34].

The present study uses data from a parent research study; namely, an optimization trial using the multiphase optimization strategy (MOST) framework [35]. MOST is an engineering-inspired framework for intervention development that strategically balances intervention effectiveness, affordability, scalability, and efficiency [36]. The ICM was developed in the course of planning the optimization trial, and then, guided by the ICM, our research team created five culturally and structurally salient behavioral intervention components to address the primary multi-level barriers to engagement along the HIV care continuum for this population as described above. The present study takes a qualitative approach and explores participants' perspectives on potential contributions of the ICM to study acceptability, feasibility, and impact. We briefly describe the three theories/approaches that comprise the ICM in the next section, followed by a description of the process of developing the ICM and its rationale.

\section{Theories and approaches that comprise the ICM}

Critical race theory is designed to illuminate contemporary racial phenomena, expand the public health discourse about the individual and social effects of institutionalized racism, and challenge racial hierarchies, including White cultural supremacy [37]. Critical race theory maintains that while systemic racism is less visible than individual racism, it is just as, if not more, influential [37]. Further, racism is baked into the fabric of society and therefore difficult to study [37]. The theory argues for the importance of "centering the margins" and focusing on individuals' lived experiences within the context of systemic racism (not just focusing on race). Moreover, critical race theory highlights the importance of counternarratives and uncovering resilience found in $A A B L$ communities. The present study was centered on AABL-PLWH and, guided by the ICM (which incorporates critical race theory), focused the content and structure of the intervention components on present and historical experiences among $A A B L$ populations that impede engagement along the HIV care continuum, such as past and present abuses of AABL populations by medical research institutions, and discrimination and systemic racism, along with fear of HIV medications, medical distrust, counter-narratives, experiences of stigma, insufficient autonomysupportive settings, and challenges accessing health services [25]. The intervention components were designed to address these types of barriers rooted in systemic racism, and to take a strengths-based approach. 
Second, harm reduction is a conceptual framework and set of practices that focus on the minimization of the physical, social, and legal harms that may affect people who use drugs and to society as a whole as a result of drug use [38]. At its core, harm reduction supports the dignity and autonomy of people who use drugs without judgment. Harm reduction is also a movement for social justice built on a belief in, and respect for, the rights of people who use drugs [39]. A harm reduction perspective allows clinicians and drug users to work together to establish goals and objectives to reduce drug-related harm, based on the notion of an individual's right to self-determination [40]. Harm reduction approaches have been found acceptable and effective in numerous past studies [41]. Because harm reduction is a way of viewing the impact of drug use on a person's psychosocial functioning, that is, harm reduction is a perspective, it is not bound to any one behavioral change technique or therapeutic theory of action [42].

Harm reduction was originally developed as an approach to reduce drug-related harms. More recently the harm reduction perspective has been applied to other types of public health concerns, such as mental health distress [43]. In the present study, we applied harm reduction to a range of behaviors, including HIV management. Indeed, PLWH's health behaviors exist within a constellation of what can be construed as potential harms to themselves and society, such as declining or taking long breaks from HIV medication, or idiosyncratic HIV medication dosing schedules (e.g., not taking medication on weekends). HIV and substance use treatment are similar in that treatment expectations are commonly absolute, leaving little room for individual autonomy. For example, the Centers for Disease Control and Prevention (CDC) recommends that PLWH initiate HIV medication immediately after diagnosis and then take "every dose, every day" to sustain HIV viral suppression [4]. Similarly, complete abstinence from substance use has historically been the predominant goal in most treatment settings [18]. While the present program of research certainly recognizes the value of taking HIV medication to achieve sustained HIV viral suppression for individual and public health benefit, it also recognizes great variability in PLWH's approaches to HIV management, and the need to discuss and explore those personal decisions to maximize health and wellbeing. Yet, messages consistent with harm reduction appear relatively uncommon in HIV treatment settings [44]. However, perfect adherence to HIV medication is not required to achieve HIV viral suppression [4]. Current regimens are highly effective and PLWH can achieve viral suppression with $80-90 \%$ adherence, or even lower depending on the regimen [4]. But, this more pragmatic approach is not yet incorporated into the CDC's definition of adherence ("every dose, every day"), and the CDC exerts a powerful influence on HIV care system policies and provider behavior. Thus, in the ICM we extended the harm reduction approach to include individuals' health care and behavioral decisions about whether or how often to take HIV medication, and how to manage other aspects of their lives and relationships in ways that might reduce or eliminate harms to the self or others, including regarding substance use. 
Self-determination theory is a macro theory of human motivation and personality that concerns the innate and fundamental needs for autonomy (people need to feel in control of their own behaviors and goals), competence (people need to gain mastery of tasks and learn different skills), and connection or relatedness (people need to experience a sense of belonging and attachment to other people) [45]. The most volitional and highest quality forms of motivation emerge when these three needs are supported by the larger environment, and self-determination theory proposes that the degree to which any of these three psychological needs is unsupported or thwarted within a social context will have a robust detrimental impact on wellness in that setting [46]. The ways in which AABL-PLWH's self-determination is commonly not fostered in society and social service and health care settings are described above.

Self-determination theory is an accepted theoretical underpinning of motivational interviewing [47]. Motivational interviewing is an evidence-based directive and collaborative counseling approach for behavior change that elicits participants' values, perspectives, and questions, identifies ambivalence and discrepancies, and corrects misinformation with permission, to thereby foster durable intrinsic motivation and readiness for change $[47,48]$. In reviews and metanalyses, motivational interviewing interventions have been found effective at clinically significant levels for a range of health behaviors [49-51]. Motivational interviewing has been found to be particularly effective with AABL populations compared to White populations [49]. As a non-coercive, strengths-based, and autonomysupportive approach, it may have utility in particular when health beliefs and emotions such as distrust/fear impede behavior change [25,31,52]. The intervention components tested used the motivational interviewing counseling approach (described below).

\section{Development of the ICM}

During the planning phases of the optimization trial, our research team formed an intervention working group and carried out an iterative intervention mapping process that included a review of the literature on barriers to the HIV care continuum for AABL-PLWH as presented above, including our own past studies $[14,25,27,31]$, and existing theories and models $[35,53]$. We identified gaps in theory, models, and interventions for this population. In particular, as noted above, structural and cultural competency are generally insufficient in existing behavioral interventions for AABL-PLWH $[6,7,54]$. Cultural competency in health care describes the ability of systems to provide care to clients with diverse values, beliefs, and behaviors, including the tailoring of health care delivery to meet patients' social, cultural, and linguistic needs [55]. Structural competence is defined as the trained ability to discern how issues defined clinically as symptoms, attitudes, or diseases, such as medication "non-compliance," trauma, depression, or smoking, represent the downstream implications of a number of upstream decisions that shape powerful factors such as health care delivery systems, zoning laws, and urban and rural infrastructures [54]. The intervention working group took the stance that cultural and structural salience in intervention content and cultural and structural competency among staff are essential to address these racial/ethnic 
disparities. Thus, to address the complex multi-level barriers that AABL-PLWH experience to the HIV care continuum and improve the acceptability, feasibility, and clinical effects of behavioral intervention components, the ICM combines critical race theory, harm reduction, and self-determination theory. Critical race theory was selected to highlight structural barriers to health, and the roles of systemic racism, counter-narratives, and resilience in health behavior for AABL-PLWH. Harm reduction was selected to underscore the importance of a non-judgmental and non-coercive approach to any positive behavior change (related to HIV, substance use, or any other health behavior). Self-determination theory was selected in light of the need for autonomy supportive approaches among AABL-PLWH. When taken together, the three theories/approaches potentially have areas of congruence and complementarity, and each theory or approach has aspects that may strengthen the others, potentially combining synergistically to create a new and useful model (Fig 1). In the center of Fig. 1 we present the primary concepts and domains identified during the process of integrating the three theories/approaches, and the boxes on the right and left of the figure comprise secondary, but important domains that bridge two of the theories.

Goals of the present study. Although critical race theory, harm reduction, and self-determination theory are well-represented in the research literature, to our knowledge these three theories/approaches have rarely, if ever, been integrated and applied in prior intervention research. Yet, when taken together, the three theories/approaches have the potential to create a new model that can be applied to health equity research. The present study explores participants' experiences in the parent optimization trial, which was grounded in the ICM, with an emphasis on uncovering and describing the ICM's contribution to, and how the ICM contributed to, study acceptability, feasibility/engagement, and potential effects. Study findings will inform future research efforts for populations that experience health inequities. In a subsequent manuscript we will explore the acceptability, feasibility, and potential impact of the specific intervention components tested in the parent intervention optimization trial and ways they can be improved from the participants' perspectives.

\section{Methods}

\section{Overview}

The present study took an ethnographic/phenomenological qualitative approach [56] and used semistructured in-depth interview data collected as part of the parent intervention optimization trial. The parent study, which had the field name "Heart to Heart 2" was carried in New York City between 2017$2021[35,36]$. As noted above, the parent study focused on AABL-PLWH with socioeconomic disadvantage who were poorly engaged along the HIV care continuum, specifically, those who did not engage in HIV care at recommended levels and who evidenced both poor adherence to HIV antiretroviral therapy and non-suppressed HIV viral load. The parent study, described by Gwadz and colleagues [35], used a fractional factorial experimental design to test the efficacy of five separate intervention 
components grounded in the ICM. It used a $2^{5-1}$ design and was comprised of 16 experimental conditions. Participants were randomly assigned to one of the 16 experimental conditions, each of which was comprised of a unique combination of intervention components (typically participants were assigned to receive 2-4 components). HIV viral suppression assessed by laboratory report was the parent study's primary outcome. The optimization objective for the optimization trial was cost-effectiveness and thus its ultimate goal of the optimization trial was to identify the most cost-effective combination of intervention components to improve rates of HIV viral suppression in this population. To date, participants have engaged in the parent study's intervention components, and the intervention optimization process is ongoing. In addition to the main qualitative results, we also present descriptive quantitative data on participants' sociodemographic and background characteristics and on study acceptability. The parent optimization trial was registered with ClinicalTrials.gov (NCT02801747). Participants gave signed informed consent for study activities. The study was approved by the Institutional Review Board at the New York University Grossman School of Medicine.

\section{Eligibility criteria for the parent study}

The parent study's inclusion criteria were 1) age 18 - 65 years; 2) African American or Black race and/or Latino/a or Hispanic ethnicity; 3) HIV diagnosed for at least 6 months; 4) HIV antiretroviral therapy adherence less than $50 \%$ in the past six weeks and detectable HIV viral load based on a laboratory report; 5) sub-optimal engagement in HIV care (operationalized as less than one visit in every four month period in the past year or > two missed visits without prior cancellation in the past year; 6) resides in the New York City metropolitan area; 7) able to conduct research activities in English or Spanish; 8) willing to provide a blood specimen at screening to assess HIV viral load; and 9) willing to be randomly assigned to 1-5 intervention components. Participants were found eligible for the parent study if they met all the inclusion criteria.

\section{Staff and training}

Study staff were diverse with respect to age, gender, race/ethnicity, and HIV status and had bachelor's or master's degrees in the social sciences (e.g., social work, public health, and psychology). All had past research experience with the population of AABL-PLWH. To promote high rates of engagement in the study, all staff members were trained in the ICM and the study ethos that aligned with the ICM which emphasized respect for autonomy and personal decisions regarding HIV medication and on providing an overall high-quality experience (e.g., staff members remembering participants' names, flexibility in rescheduling, prompt compensation, acknowledgement that participants' time is as valuable as staff time, and refreshments provided in the waiting area and during sessions or groups). Thus, staff were trained to be both structurally and culturally competent to foster engagement and trust and foster the behavior change process. 
Brief description of the components. The intervention components were Component A: motivational interviewing sessions was designed to specific motivational interviewing techniques to address salient, including culturally salient health beliefs (e.g., outcome expectancies, self-efficacy, medical distrust) and emotions (e.g., concerns/fears of HIV medication) to foster durable intrinsic motivation for behavior change. Component B: pre-adherence skill building was designed to help participants build behavioral skills to manage HIV medication adherence such as habits while attending to cultural and structural factors that can impede adherence (e.g., lack of private living space). Component C: peer mentorship was facilitated by a "successful" peer mentor (i.e., a PLWH demographically similar to study participants who had consistently engaged in care and was taking HIV medication with high levels of adherence) and sought to provide peer modeling of and shape peer norms regarding HIV management (primary goals), and provide social support and combat stigma (secondary goals). Peer mentors elicited and addressed the types of barriers AABL-PLWH experience to engagement. Component $D$ : focused support groups were designed to provide social support and reduced stigma regarding care and HIV medication use, including culturally salient factors that impede engagement such as medical distrust and fear. Component $\mathrm{E}$ : navigation was designed to identify and ameliorate structural barriers to care and HIV medication. In this factorial design, all components had two "levels." Components A-D's levels were off/on (participant did not receive/participant did receive), and Component E's two levels were short navigation (three months) vs. long navigation (six months). The study overall emphasized non-judgment and the project's tag line, found on the project logo and recruitment materials, was "No pressure, no judgment." Thus, the project took an active and explicit approach to non-judgment.

\section{Procedures for the parent optimization trial}

Recruitment into the parent optimization trial. The recruitment approach for the parent study comprised a hybrid sampling strategy that included peer-to-peer recruitment; direct recruitment by study staff members in HIV service, HIV housing, and other community-based organizations; and advertisements in a local free newspaper. Peer recruitment was the primary sampling approach. Peer recruitment was tracked with a coupon system that linked the recruiter to the recruit, and recruiters received modest compensation for recruitment ( $\$ 15 /$ recruit). Most enrolled participants were recruited by peers $(75 \%) ; 9 \%$ were recruited through newspaper ads, and $16 \%$ through other means.

Screening, enrollment, intervention activities, and follow-up assessments

Participants were screened for eligibility after providing informed consent. Screening included assessment of HIV viral load levels via laboratory report obtained from a commercial laboratory. Those 
found eligible for the parent study provided signed informed consent, and completed a structured baseline assessment battery lasting 60-90 minutes. The baseline was conducted in the Research Electronic Data Capture (REDCap) platform. REDCAP is a cloud-based platform for data capture designed for clinical research $[57,58]$. After completing the baseline assessment, participants were randomly assigned to an intervention condition. Participants were randomly assigned to one of 16 different experimental conditions, each comprised of a different combination of the five intervention components [35]. Most experimental conditions were comprised of 2-4 intervention components. All participants received a core health education session, the standard of care. The intervention components were individualized and flexible, and did not assume that participants wished to or were ready to take HIV antiretroviral therapy at the present time. The period during which participants engaged in intervention activities ranged from 4 to 8 months. Regarding the timing of intervention activities, navigation was provided first, to begin to address structural barriers to engagement along the HIV care continuum (all participants received either 3 or 6 months of navigation). Counseling sessions were scheduled next for those randomly assigned to receive that component. Peer mentorship and focused support groups could be administered in the same time period (although not on the same days), and pre-adherence skill building was provided last for those assigned to receive it.

Participants received follow-up assessments and 4-, 8-, and 12-months post-baseline, comprised of a structured interview and HIV viral load test at a commercial laboratory (at 8-, and 12-months). Thus, participants were enrolled in the Heart to Heart 2 study for 12 months. In-person study activities took place in confidential offices at a project field site in lower Manhattan in New York City. Participants were compensated \$15 for a screening interview, \$15 for providing the blood specimen for HIV viral load testing, \$25 for baseline and follow-up assessments, and \$25 for each intervention session or activity, along with funds for local round-trip public transportation.

\section{Effects of the COVID-19 pandemic on the parent study}

The first case of COVID-19 was diagnosed in New York City on March 1, 2020. On March 12, 2020, inperson activities with human subjects were suspended at New York University, although virtual activities could continue with IRB-approval. At this point in the study, 241/512 (47\%) had completed participation in the study, with the remainder still scheduled to attend intervention activities and/or follow-up assessments. With the exception of focused support groups, which were not feasible given participants' lack of smartphone and computer access [59], intervention components and follow-up assessments were carried out in a virtual format. Because we could not escort participants to a commercial laboratory because travel to laboratories was restricted, we requested that participants provide a recent laboratory report from their clinic for which they would be compensated $\$ 30$. Yet because early in the pandemic HIV services and travel were disrupted due to the public health order to remain at home, it was commonly challenging for participants to carry out laboratory tests and obtain reports. The COVID-19 pandemic 
resulted in some delays in engagement in study activities and reduced the proportion that provided HIV viral load results modestly.

\section{Procedures and materials for the present study}

Selection of participants for qualitative interviews. A total of 2-4 participants from each of the 16 experimental conditions were randomly selected for two qualitative, semi-structured, in-depth interviews, one early in the study (within 5-7 months of enrollment) and another at study completion. The first qualitative interview focused mainly on participants' general experiences living with HIV and with engagement along the HIV care continuum, and the second on perspectives on the parent study's activities. Random selection for the qualitative interview, rather than a selection method more common in qualitative research such as purposive sampling, was intended to serve the needs of the parent study. Nonetheless, random selection and purposive sampling for maximum variability have similar goals; namely, variability in participant characteristic and experiences. The qualitative interviews sought to understand participants' experience in the range of intervention conditions and who received a range of intervention components. The qualitative interviews were audio-recorded and professionally transcribed verbatim. Individuals were compensated $\$ 25$ for each qualitative interview, along with funds for local round-trip public transportation. A total of 46 participants engaged in the first qualitative interview and 32 of these also completed the second interview (thus 70\% participated in both interviews). Interviews were conducted in-person at the study field site prior to the COVID-19 restrictions, and on the phone after restrictions on in-person activities were implemented.

\section{Qualitative semi-structured interview guide}

The in-depth interviews were guided by a semi-structured interview guide developed by the research team, which included experts on AABL-PLWH and the HIV care continuum. The guide was based on a review of the literature and guided by the ICM. The guide was pilot tested prior to administration and refined. It was structured as a series of questions and prompts, starting with more general questions and moving to more specific ones. Throughout the interview process, the interview guide was updated to reflect newly emergent concepts (e.g., feeling pressured to take HIV medication and its effects). The guide had four sections: 1) general experiences with the study (e.g., To start off, what was it that led you to agree to participate in the study? What stands out to you most about the project so far? What have you like? Disliked? Have you been involved in similar projects? How is this study similar/different? What do you think about the staff in general?; 2) emotional or behavioral effects of study_participation or recent changes concurrent with study participation, if any (e.g., Have you taken HIV medications since you joined the Heart to Heart 2 study? It's OK if you haven't. We just want to understand what's going on with you now. Why or why not?; What factors played a role in your deciding to take HIV medications at this time, whether related to the Heart to Heart 2 study or other factors?, Since you've been involved with the 
study, has anything changed about the way you think about HIV medication?); 3) exploration of the specific intervention components the participant was randomly assigned to receive (e.g., What do you remember about this component?, Can you tell me what kinds of things you discussed? Describe whether this component useful to you or not useful?); and 4) ways the study could be improved (e.g., We want to ask a few more questions about how we can improve. What do you think should be included in the Heart to Heart 2 study that wasn't included?). The present study focuses on data from the first two sections of the guide, and data collected in response to the second two sections will be presented in a future study. The interview guide is provided as Supplemental Material.

\section{Qualitative Data Analysis}

The strategy used a directed content analysis approach that was both inductive and theory-driven [60]. First, a primary researcher trained in medical anthropology analyzed interview transcripts and developed an initial start-code list and operational definitions for each code, informed by the theoretical and conceptual perspectives guiding the study [61]; namely, the underlying ICM approach and the theory of triadic influence, which organizes barriers to and facilitators of engagement along the HIV care continuum as structural-, social-, or individual/attitudinal-level influences. Thus, codes included those related to culture and race/ethnicity (e.g., experiences of discrimination, medical distrust, counternarratives), substance use management, and autonomy, competence, and relatedness, as well as about other factors that promote or impede engagement along the HIV care continuum (e.g., housing, mental health distress, and poverty). Then, the primary analyst coded approximately 20 transcripts using the start-code list. Next, two additional trained qualitative researchers coded a subset of the interview transcripts and met frequently with the primary data analyst. Codes were further refined and elaborated upon, and discrepancies were resolved by consensus. After resolution of discrepancies, each transcript was then recoded using the final coding frame. Then, in an iterative process and in collaboration with an interpretive community made up of members of the research team, codes were combined into larger themes and sub-themes $[62,63]$.

Regarding positionality and methodological rigor, the research team was made up of men and women from White, African American/Black, Asian, and Latino/a backgrounds. The primary data analyst was a member of the research team trained as a medical anthropologist and experienced with HIV research, including with this subpopulation of AABL-PLWH. Positionality challenges related to sex, gender, race/ethnicity, power, health, socioeconomic status, and privilege were intentionally addressed throughout the data collection process through reflection and training, which focused on how these types of issues might impact the interviewing process and data analysis [64, 65]. Although we used the random sampling method for the qualitative interview based on the demands of the parent study, we attended to issues of maximum variation in sample characteristics [66] as one aspect of trustworthiness [67]. Methodological rigor of the analysis was further maintained through an audit trail of process and analytic memos and 
periodic debriefing with the larger research team, which included PLWH and experts in long-term HIV survivorship and HIV medication adherence, as well as member checking with AABL-PLWH; feedback from the member checking was incorporated back into the results [56].

\section{Quantitative measures}

We assessed age, sex assigned at birth, gender identity, sexual minority status (i.e., identifies as gay, lesbian, bisexual, queer, or other non-heterosexual identity), race/ethnicity, housing status, history of incarceration (yes/no), indications of extreme poverty (how often unable to pay for necessities in the past year and food insecurity) with structured instruments developed for populations in high-risk contexts [68]. The Adverse Childhood Experiences Scale- revised (ACES-R) 14-item scale was to assess early life experiences such as peer victimization, neighborhood disorder, physical abuse, neglect, and sexual abuse [69]. We used a version of the HIV Cost and Services Utilization Study (HCSUS) [70] instrument to assess years since first HIV diagnosis; years since first initiated ART; number of months since last HIV medication dose (if not on HIV medication at screening). HIV viral load was assessed with a laboratory report and suppressed viral load was coded as $<200$ copies $/ \mathrm{mL}$. Substance use patterns were assessed by the World Health Organization Alcohol, Smoking and Substance Involvement Screening Test (WHO ASSIST) [71]. Using established thresholds, symptoms of depression were assessed with the Patient Health Questionnaire depression module (PHQ- 9) and coded as likely depression (yes/no) [72]. The Generalized Anxiety Disorder scale (GAD-7) was used to assess symptoms of anxiety and coded as coded as likely anxiety (yes/no) [73]. The Primary Care PTSD Screen to assess symptoms of PTSD, coded as likely PTSD (yes/no) [74]. Study acceptability was assessed using the 12item Client Satisfaction Survey [75]. Feasibility was defined as the proportion of participants who completed study assessments.

\section{Quantitative data analyses}

We used descriptive statistics to summarize socio-demographic and background characteristics and study acceptability.

\section{Results}

Participants' sociodemographic and background characteristics are found in Table 1. Participants were 49 years old, on average ( $\mathrm{SD}=9$ years). Most $(78 \%)$ were assigned male sex at birth. Approximately a third (33\%) were sexual and/or gender minorities. The majority (76\%) were African American or Black and the remainder were Latino. Rates of adverse childhood experiences ranged from 0-14 (mean=4, SD=3 experiences). Indications of low-socioeconomic status and extreme poverty were common: Only $17 \%$ were employed, nearly half ( $46 \%)$ had run out of funds for necessities at least monthly in the past year, 
and most (85\%) experienced food insecurity often or sometimes in past year. Less than half (52\%) were not stably housed. Participants had been diagnosed with HIV 19 years ago, on average ( $S D=7$ years). All had taken HIV medication in the past. The longest duration of sustained HIV medication use was 45 months ( $S D=63$ months). Current substance use was common: approximately half (54\%) used alcohol at a moderate-to-high-risk level based on The World Health Organization ASSIST measure scoring criteria, $61 \%$ used cannabis at a moderate-to-high-risk level, and $63 \%$ used cocaine or crack use at a moderate-tohigh-risk level. Less than $10 \%$ injected drugs in their lifetimes or the past three months. Most (78\%) engaged in substance use treatment in the past. Approximately one third of the sample or less reported likely depression, anxiety, or post-traumatic stress disorder (PTSD). A total of $40 \%$ evidenced suppressed HIV viral load assessed via a lab report at the 8- and/or 12-month follow-up period. 


\begin{tabular}{|l|c|}
\hline \multicolumn{2}{|c|}{ Table 1. Participant sociodemographic and background characteristics (N=46) } \\
\hline \multicolumn{1}{|c|}{ M (SD) or \% } \\
\hline Age (range 23 - 62 years) & $48.9(8.74)$ \\
\hline Sex assigned at birth & 21.7 \\
\hline Female & 78.3 \\
\hline Male & 32.6 \\
\hline Sexual and/or gender minority status & 4.3 \\
\hline Transgender gender identity, gender fluid, gender non-conforming & 76.1 \\
\hline African American or Black (non-Latino/Hispanic) & 21.7 \\
\hline Latino or Hispanic & 47.8 \\
\hline $\begin{array}{l}\text { Stable housing (has their own home or apartment, including funded by } \\
\text { government programs or benefits) }\end{array}$ & \\
\hline Adverse Childhood Experiences (ACES-R) score (range 0-14) & $3.56(3.33)$ \\
\hline Indications of low socioeconomic status and extreme poverty & 17.4 \\
\hline Working full-time or part-time off-the-books or on-the-books & 45.7 \\
\hline Ran out of funds for necessities monthly or more in the past year & 84.8 \\
\hline Food insecurity often or sometimes in past year & 17.4 \\
\hline Engaged in transactional sex - past year & $18.6(7.18)$ \\
\hline HIV-related factors & $18.5[13.3$ \\
\hline Years since HIV diagnosis at enrollment (range 3.0 - 30.0 years) & $24.0]$ \\
\hline Median [Q1, Q3] & 100 \\
\hline Took HIV medication in the past & $10.6(17.8)$ \\
\hline Times stopped/started HIV medication in the past (range 0 - 100 times) & $45.0(62.7)$ \\
\hline $\begin{array}{l}\text { Longest duration of sustained HIV medication, in months (range 0-264 } \\
\text { months) }\end{array}$ & \\
\hline Psychosocial risk and protective factors & 54.3 \\
\hline Alcohol use at a moderate-to-high-risk level & 60.9 \\
\hline Cannabis use at a moderate-to-high-risk level & 63.0 \\
\hline Cocaine or crack use at a moderate-to-high-risk level & 28.3 \\
\hline $\begin{array}{l}\text { Use of other drugs (not including alcohol, cannabis, cocaine/crack) at a } \\
\text { moderate-to-high-risk level }\end{array}$ & 87.0 \\
\hline Never injected drugs & 6.5 \\
\hline Injection drug use lifetime, but not in the past 3 months & 6.5 \\
\hline Injection drug use - past 3 months & 21.7 \\
\hline Participated in substance use treatment in the past & 10.9 \\
\hline Likely depression & 34.8 \\
\hline Likely anxiety & 4.28 \\
\hline Likely PTSD & 40.0 \\
\hline HIV viral load & \\
\hline HIV viral load level at enrollment (log 10 transformed) & \\
\hline Suppressed HIV viral load at 8- and/or 12- month follow-up assessment & \\
\hline
\end{tabular}

In Table 2 we present participants' acceptability ratings of aspects of the study overall at the final followup assessment for the entire sample. Acceptability ratings were high (> 70\%). Regarding feasibility, despite disruptions due to the COVID-19 pandemic as described above, assessment follow-up rates were high: $83.4 \%$ completed the 4-month, $81.1 \%$ completed the 8-month, and 80.7\% completed the 12-month follow-up assessment. 


\section{Table 2. Acceptability ratings at the final follow-up assessment ( $N=411)$}

Overall, I think the activities and services in the Heart to Heart 2 project are good to 90.0 excellent

The information I have received in the project has been helpful or very helpful

The staff of the project have answered my questions most of the time to all the time The project staff treats me like I am an individual with unique needs and concerns most times to all the time

The project staff respects my privacy most times to all the time

The project staff understand the needs of people of my racial, ethnic, or cultural group most times to all the time

(If sexual/gender minority status) The project staff understand the needs of people who identify as LGBTQ (lesbian, gay, bisexual, transgender and queer)

(If female) The project staff understand the needs of women most times to all the time

(If $<36$ years old) The project staff understand the needs of younger people $(<36$

years old) most times to all the time

(If $>50$ years old) The project staff understand the needs of older people ( $\geq 50$ years

old) most times to all the time

Participation in the Heart to Heart 2 project affected my decision to regularly attend

HIV medical care somewhat to a great deal

Participation in the Heart to Heart 2 project affected my decision about whether or not to start HIV medication somewhat to a great deal

\section{Overview of results}

Participants described managing a confluence of recurring challenges and crises, all exacerbated by chronic poverty, throughout the time they were enrolled in the Heart to Heart 2 project. These commonly included homelessness and/or poor quality or unstable housing, relationship instability, involvement with probation and parole systems, histories of trauma exacerbated by current trauma, underlying physical health comorbidities in addition to HIV, challenges with substance use management and in some cases, 
hazardous substance use, the need to sell HIV medication to meet basic needs, and severe mental health distress. This attention in the present study to structural factors such as poverty and housing is consistent with the ICM which emphasizes structural competence. Nonetheless, even in this challenging context, the majority of participants were still able to reflect on their own strengths and resilience, perhaps reflecting the ICM, which incorporated a strengths-based approach. Further, we found participants maintained both the desire and ability to make changes in health behavior and other aspects of their lives consistent with their own values, including within the "safe space" that they reported the project provided. Participants overwhelmingly emphasized that the Heart to Heart 2 project provided a space within which they felt welcomed, individually cared for, and, ultimately, within which they were able to reflect on both their emotional and physical health, including their management of substance use, anxiety and depression, personal relationships, HIV, underlying health conditions, and in many cases their willingness, ability, and/or desire to re-initiate HIV medication or to increase HIV medication adherence in order to achieve HIV viral suppression. Even when participants did not elect to initiate HIV medication or increase the number of HIV medication doses they were taking during the project, they reported that engagement in project activities typically resulted in other types of psychosocial, emotional, or tangible improvements. Consistent with the ICM, participants were encouraged to stay engaged in the study even if they elected not to focus on or work toward the study's primary outcome, HIV viral suppression, without experiencing pressure or judgment from project staff. Generally, participants engaged in frank discussions of their health decisions (e.g., not taking HIV medication) and contextual challenges (e.g., selling HIV medication, substance use) with project staff, including discussing those behaviors not typically considered socially desirable or socially acceptable, which may reflect the ICM and its emphasis on non-judgment, harm reduction, and personal autonomy.

We organized results into the following four inter-related themes: the importance of feeling understood and validated as a whole person and in context; experiences of trustworthiness and trust; opportunities for self-reflection on a range of topics and its effects; and support of personal autonomy and its effects on motivation and decisions. The importance of nonjudgment was prominent in each theme. We also provide findings on the context of participants' lives in the sections that follow and highlighted the ways the results reflect the ICM. In reporting the qualitative results, we present findings pertaining to participants' experiences in the project as whole, with some references to specific intervention components for clarity. Gender-neutral pronouns (they/them/theirs) were used in the sections that follow because we did not assess which pronoun series participants used to describe themselves. We used pseudonyms and changed or obscured identifying details to maintain participants' confidentiality.

\section{The importance of feeling understood and validated as a whole person and in context}

Participants emphasized the important role that the contexts of their lives, as noted above, and the characteristics of institutional settings they commonly engaged in, had on behavior and wellbeing. First, 
they emphasized that social isolation was both chronic and extreme. They reported being generally unable to connect with healthcare, mental health, and other service providers in a manner that was nontransactional, non-judgmental, and meaningful, with one exception; namely, support groups at local community-based organizations oriented toward working specifically with PLWH. Overall, participants felt unwelcome and devalued in health care settings, and were typically hesitant to openly discuss issues such as mental health and substance use with healthcare providers and social service agencies. Participants reported that in many service settings, and particularly in HIV care settings, they frequently experienced feelings of invalidation and lack of individualized care, describing instances wherein they felt like a number, and were treated as "less than human." This typically resulted in an erosion of their intrinsic motivation to prioritize themselves or their health, which in many cases led to feeling less motivated, rather than more motivated, to improve their HIV medication adherence patterns after engaging in health care settings.

In contrast, when asked to reflect upon their experiences during the Heart to Heart 2 project, participants typically discussed feeling understood as an individual, and, in many cases, as a whole person. They commonly reported that the project was one of the first times they felt viewed in a professional setting as a complex person with well thought-out and worthwhile perspectives and needs. As shown in Fig. 1, the ICM emphasizes, in part, individualized care, participant dignity, and reduction of stigma. Participants indeed did commonly experience relationships with project staff as de-stigmatizing, mutually respectful, possibly dignity enhancing, and, in many cases, caring. This, in turn, fostered a clinical context in which they could explore aspects of their lives they generally experienced as underappreciated, disregarded, and stigmatized in most professional settings, in relative safety.

Upton, a Black, gay, cisgender male in their late 40s, who had been living with HIV for 10 years, described the importance of their larger context and the cascading effect that poor quality housing could have on HIV medication adherence, by triggering depression.

I moved to this room, it's horrible, in the Bronx. It's very hot, you can't cook, you have to buy every meal. [...] It's so much more expensive having to buy every meal, every day of the week. [...] This place it kind of makes it hard, but I'm trying to keep on the up. Because I know if I go down [get depressed], then my adherence is going to get thrown off. [...] If I get to my depression or I just - because there's been times the [medication] bottle has just been sitting there, and I didn't sell it, and I still didn't take it. That's just the only battle. And that'd be my mental health issues, and hopefully I don't - I could stay on top of that. The weed helps. You know what I mean? I'm just being real. 
Thus, Upton highlighted the importance of eliciting and understanding the context of participants' lives, including how poverty can create contexts such as poor housing quality that are not conducive to HIV medication adherence, and how entities in the larger environment, such as corrupt pharmacies that buy HIV medication from patients, interfere with health behavior. Upton described a personal harm reduction approach to preventing their selling HIV medication to corrupt pharmacies: In order to prevent themselves from diverting their HIV medication, they would "like punch the foil open once I pick it up from the pharmacy." This is because once the foil on the pill bottle was punctured, it would not be possible to sell the bottle, and Upton would be more likely to adhere to their medication regimen. They continued, "Even though I may say I'm not going to sell it, but - and even though there's no thought of selling it, [I] punch it anyway." Indeed, guided by the ICM, the intervention components were designed to elicit and address or circumvent these types of structural and contextual factors, and prompt participants to develop harm reduction strategies.

Simone was a Black, heterosexual, cisgender female in their early 40 s who had been living with HIV for approximately 15 years, and who struggled with depression. Simone described a history of very difficult experiences with medical providers and managing health care systems, including numerous cases where providers pressed them to make certain medical decisions, but did not truly understand Simone's needs. They described:

The doctor actually gave me a prescription that I'm allergic to [related to an egg allergy]. That means that you're not paying attention to my chart. Like these are the things that you go through [in HIV care settings], and if you're not an assertive person like I am, [if] you're not paying attention, [if] you're not reading these papers, [if] you're not reading what they're ordering, [if] you're not reading what you're signing, you're going to end up getting a flu shot that you're allergic to. So that just made me feel like, okay, you guys are just not [paying attention].

Simone had not taken HIV medication for over a year at the time they enrolled in the study. They described their experience in Heart to Heart 2 as "personalized," in contrast to the typical medical setting, and these personalized experiences contributed to their deciding to access treatment for depression and, sometime later, re-initiate HIV medication.

Hank, a Black, gay, cisgender male in their early 50s, who had been living with HIV for approximately 10 years, contrasted their experiences in the research project with typical health care setting encounters. 
They noted a marked lack of social and structural stigma in their interactions with Heart to Heart 2 project staff, consistent with the ICM:

And you know, just in passing I spoke to like the receptionist [at the project], the people that log them [participants] in, and you know, it's like you don't feel like a pariah, you don't feel like nobody's scared of you because you're HIV positive. It's like people talk to you like a real person, and that matters more than anything. [...] People were treating me like I'm a person instead of a number. [...] Other than that, it's just, I just feel comfortable [at Heart to Heart 2]. Usually when you go to places like this [that serve PLWH], people make you feel like, you know, hands off. They don't make you feel comfortable at all. It's like totally psychological, and sometimes, you know, you ain't in the mood for that shit.

Relatedness (i.e., social relationships) is one important aspect of the ICM. Like with Hank, many participants described the ability to develop meaningful, ongoing connections with project staff as a critical part of their experiences with the project and the foundation, in turn, for their being willing and able to address a broad range of HIV medication-related struggles in a holistic manner.

On the other hand, participants commonly expressed frustration that their primary care providers and other social service providers were not better able to see their HIV care and HIV medication adherence struggles in a larger context. In particular, they experienced their providers as "dismissive" of a number of issues participants considered vital, such as housing insecurity, personal relationships, substance use, and legal problems. Participants reported providers appeared to see these types of concerns as peripheral or even unrelated to HIV management. Yet, participants were clear these issues were directly related to HIV care and medication, and the lack of such recognition commonly left participants feeling overlooked, frustrated, or rejected. In contrast, the ICM highlights the importance of understanding a participant or client's larger context, including structural factors that may affect health behavior. Jared, a Black, heterosexual, cisgender male in their early 60s, who was diagnosed with HIV at the age of 40 and who was struggling with medication adherence and substance use issues while in the Heart to Heart 2 project, drew a stark contrast between the connections forged during their time with the project and with other settings. They repeatedly stressed the importance of feeling seen and heard by all Heart to Heart 2 staff members alike:

Because the basic thing here with you all is that you listen. All of you all. Even you. I'm looking at you. You're listening to me. You ain't trying to blow me by. Anybody's trying to blow me by [1] would get up and say have a nice day. I'm like that. Quick. But you listen. I seen that when I first walked in. It's important. Because people are hurting, you never know. See, when you don't listen to someone, that - I have seen 
people in my life, I'll be honest with you, I've seen like six or seven people commit suicide because nobody listened to them [...] And that's why I love this place, because you'll listen. Every last one of you that work here, you're listening, and then you'll give back your feedback. I never got no bad [unhelpful] feedback from none of y'all.

Thus, Jared highlighted the importance of being "listened to" as a precursor to receiving feedback that might assist them in achieving their health goals. This experience of being listened to and heard may reflect the ICM in that participants' larger contexts are considered a vital part of the clinical encounter. We found that when participants felt they were being genuinely listened to, the level of investment they felt by staff translated to the participant developing a deeper level of investment in themselves.

It follows that since the ICM highlights the importance of eliciting and understanding a participant as a whole person and in context, participants are more than just an "HIV positive person." Results indicated that having a space where participants experienced individualized services that took the larger context into consideration, while also supporting autonomy, commonly fostered their abilities to see HIV and HIV medication as aspects of their lives, and therefore, to reduce the sense of being defined solely by their HIV status. Steven was a Black, heterosexual, cisgender male in their early 50 s, who had been living with HIV for 20 years, and for whom "going to a doctor is a reminder" of their HIV status. For Steven, the ability during the Heart to Heart 2 project to have an "open dialogue" with chances to "branch off" into other areas of their life presented an "unexpected opportunity" to connect the painful emotions related to living with HIV and their experiences in typical HIV service settings more directly with their ongoing HIV medication adherence challenges. In the following quote, they refer to the study in general, and to Component D: focused support groups:

You come to a place where [you can engage with] people with the [HIV] virus and shit. And you're offered a chance with people with the virus to talk and feel relaxed and comfortable. There's not that many places that you can feel human, because you've got to understand: There are times you feel less than human, which is why a lot of people don't take their medication and everything, because they want to forget. They want to be - I'm just normal. I'm like everybody else. So, you don't take medication, and you don't present to doctors and do what you want to do to live that fantasy of being everybody else. And you put yourself in jeopardy. Truthfully, you're putting more people in jeopardy.

As with most participants, feelings of validation that their life was seen in context, that they were valued as a whole person, and of connectedness with the project staff allowed for more open and honest conversations about a range of issues directly and indirectly associated with HIV care and HIV 
medication adherence. Further, the sense of acceptance and connectedness that resulted from the intervention activities grounded in the ICM were reported to increase participants' view on the acceptability of intervention components, as well as the likelihood that participants would continue to actively engage with the Heart to Heart 2 project over time; that is, study feasibility.

\section{Experiences of trustworthiness and trust}

As noted above, distrust of health care systems, HIV medications, and counter-narratives about the causes of HIV and its treatments are very common among AALB-PLWH, while distrust in actual health care providers is secondary. Yet, participants' trust in the project and the project staff are critical for perceived acceptability of services, ongoing engagement and thus study feasibility, and effective clinical service provision. Trust is a central precursor to effective counseling interventions and productive patientprovider relationships, as noted above. The ICM was designed in large measure to create a research project that was worthy of trust and to build trust. In part this was addressed by eliciting and understanding the valid reasons for medical distrust and counter-narratives among AABL-PLWH, since medical distrust and distrust of research projects are related. Guided by the ICM, the project staff sought to build participants' trust and communicate their trust in the participants to make their own health decisions, even in the context of medical distrust (which the project sought to elicit but not necessarily to question or change). Thus, to some extent trust between the project and participants was built by eliciting, discussing, and understanding the valid reasons for distrust and counter-narratives, and by the project expressing trust that participants would make the right decisions for themselves.

Participants frequently discussed the importance of trust and honesty in medical care and social services. They provided numerous examples of times when they either had or had not trusted or been honest with others, and also times when they had and had not been honest with themselves. Consistent with the intentions of the ICM, participants commonly experienced the Heart to Heart 2 project as an environment where they could speak openly and honestly about matters related to their physical and mental health care that, in the past, they typically felt were off-limits or that they avoided out of an abundance of caution. Of vital importance, participants noted they experienced being trusted and being seen as trustworthy in the project. For example, they experienced project staff as assuming that they (the participants) were experts on their own health and could and should make their own health-related decisions. This perspective, in turn, contributed to feelings of confidence and self-efficacy with respect to these health decisions. In contrast, participants reported commonly experiencing great pain and frustration in health care settings in cases where they were not trusted to be expert on their own health. This theme of the importance of trust and trustworthiness was noted in discussions about relationships with HIV medical providers, project staff, and other support staff in participants' lives. Upton, introduced above, described a long history of significant mental health concerns and complicated substance use patterns, coupled with pervasive homelessness, which began when they disconnected from their family 
decades prior. Upton explained that all of these experiences made it very difficult to remain in medical or mental health care on a continuous basis, particularly over the past five or six years. They discussed how they had been selling their HIV medication when they needed money for necessities, and sometimes for substances. Upton described being able to discuss these types of experiences honestly and without judgment during the Heart to Heart 2 project, suggesting Upton found the project trustworthy. Upton described that those honest discussions in and of themselves helped to develop motivation for their personal HIV-related health goals.

Even when I didn't take it [HIV medication] - I mean I remember them times - when was it? Especially late last year, early this year, January, when I actually didn't take a bottle, and I was just totally honest - I think I had a meeting with [my navigator] right around the next day I think I sold the bottle.... And I didn't feel judged. She said, "I'm so glad you're honest and open with me about it." I didn't feel pressure or discrimination at all.

Similarly, Ronald, introduced above, described the project as a place where they learned a great deal about themselves, their decisions, and their motivations. They noted the environment provided space for them to be honest with the project staff, which led Ronald to become more honest with themselves, and also more honest with their health care providers and others in their life. They described feeling trusted by staff to be a reliable reporter of their own experiences, including related to substance use problems, and that experiencing that trust helped them to prioritize their own health:

[Heart to Heart 2 has] taught me a lot, man. It's taught me that I need to be honest with myself. I need to be true with me about everything I do in life. Even with this young lady I met [a new romantic interest], even with myself. I should be number one in this world because without me, I can't make anyone else happy. [...] That's just the outcome of life, man. I want to be somebody in this world. I want to leave a legacy. [...] I want my family to say wow, at least he went bad and then he became someone and he did something [positive]. He left this for his nieces. That's my plan.

Wallace, a Black, gay, cisgender male in their mid-40s, who had been living with HIV for decades, described their life history as one of being in service to others, coupled with a lengthy history of substance use, unstable housing, and mental health issues. They saw the environment in the research project as one that engendered a feeling of trust, which in turn enabled them to open up about their myriad life experiences in a way Wallace had never experienced before, reinforcing a sense of trust they were developing within: 
[Being able to talk about things not directly related to my HIV medication] is what always happens when I come here. And that's why I say it's very helpful, because I don't go anywhere else and talk like this. [...] So, whenever I come here, I'm able to process some stuff that I don't process anywhere else. I think that Heart to Heart creates a level of comfortability for people to be able to open up. Just the vibe and the spirit from your workers. [...] And some places you go to it's just very business and there's a very fine line. [...] Like here, I come, and I just feel like I'm able to talk to you guys. I can't explain it. Maybe it's just the vibe here is much more laid back than some of other places. So, you don't feel as though you're restricted well, I'm here for this and that's that. [...] And some places it's like, well you're not here to talk about your partner. Talk about your medication. But they don't see past that.

Thus, in addition to project staff seeking to build trust with participants and convey trust for participants' decisions, intervention activities grounded in the ICM commonly fostered participants' own trust in and honesty with themselves. This honesty with oneself was described by a number of participants as a critical aspect of their behavior change decisions and processes. We examine the role of a related concept, self-reflection, in more detail in the theme described below.

\section{Opportunities for self-reflection on a range of topics and its effects}

Aspects of the ICM, including non-judgment, trust building, compassion, and focus on the whole person were intended, in part, to foster open and honest self-reflection. Indeed, participants commonly reported significant, meaningful self-reflection during their time in the project. In contrast, participants generally did not recall being asked about aspects of their lives unrelated to HIV in most other social service and health care settings. This, in turn, created a sense in those environments that their multilayered lived experiences should be kept separate from their HIV care management. Moreover, while the ICM assumed that emotions are an important aspect of HIV management, participants commonly stated they had never been asked about their emotional relationships with HIV medication or their HIV care in these other settings. Participants noted that reflecting on these fundamental questions about the experience of living with HIV allowed them to hear some of their own thoughts out loud for the first time, giving them the opportunity to notice patterns of behaviors in their lives. For some, these new insights about patterns of behavior and their causes precipitated behavior changes in HIV medication use, HIV care, mental health support seeking behavior, and substance use management.

In some cases, self-reflection, an intended outgrowth of the ICM, was directly linked to a new awareness of the importance of autonomy and self-determination in health care decisions. Samuel, a Black, gay, 
cisgender male in their late 30s, who had been living with HIV for nearly 20 years, said they experienced a major shift in the way they looked at their life during the study:

The counselor, she's a real sweetheart. She never judged me, and never made a decision for me. She just asked me, "Well, how do you feel that decision has affected you?" And I never really thought about that. It was just a life-changing moment. Something just clicked. Like, yeah, that [the decision] is still not helping me. So, I want to do everything I can to help me, even though I still have to go through these dilemmas. I'm going to make sure that I'm all right.

Further, non-judgement may be essential for self-reflection in this context. Indeed, the importance of nonjudgment was present in each of the themes described in this section.

Emmanuel was a Latino, bisexual, gender fluid male in their early 40 s, who had been living with HIV for approximately 10 years, and who had struggled for most of those years with remaining in HIV care and adhering to HIV medication. They explained the complex nature of their difficulties remaining in HIV care prior to joining the study, which included difficulties accepting their HIV status, feeling judged by multiple providers due to their sexual orientation and gender identity, a perceived lack of confidentiality in some service provider settings, and extensive substance use over the years. As they reflected on their time in the Heart to Heart 2 project, they said they experienced, "...a warm welcome when I came. You want some coffee? You want some tea? I was like, oh my god, that's nice. I wasn't [expecting that]." These elements of the study were intended to foster relatedness, one aspect of the ICM. They went on to discuss their experience of being asked questions "they had never been asked before" regarding what they thought was best for them, recalling that, "they asked me what I wanted to do with my life". Emmanuel said the project environment and the direct questions asked in the intervention components, both of which communicated caring and acceptance to them, opened up space for them to reflect on their life and health:

It makes you think about your life.... The generosity, the caring-ness you know? Somebody that doesn't even know you - they care about you, and to listen to you - what do you want? What do you want to do? You don't get asked them [usual] questions. People judge. People assume [they] already [know] what you want instead of asking you what you want. They're judging for you, or they're making a decision for you, and I don't want nobody to make a decision for me. Ask me what I want? Then you can point me to - if you have another option that we can work around or work with, then I have no problem with that. I have no problem with listening to what you have to say... I don't ever feel pressure here. No, I feel love here. 
For Emmanuel, therefore, positive relationships with the project and project staff and non-judgment were preconditions for engagement in clinical services that, in turn, spurred self-reflection. Further, selfdetermination, an aspect of the ICM, was clearly a deeply held value for Emmanuel.

William, a Black, heterosexual, cisgender male in their early 50 s, who had been living with HIV for 20 years, discussed developing a pervasive substance use "addiction" at an early age, which led them to leave home and to become estranged from their family for more than 30 years. During that time, and due largely to their substance use challenges, William was diagnosed with HIV and struggled to remain in HIV care and on HIV medication. Further, they subsequently experienced homelessness for several years, but, more recently, was stably housed with a family member they had reconnected with. William looked back on their time before starting the Heart to Heart 2 study and reflected on the changes they had experienced in their life since starting the study, related in large measure to self-reflection that took place during study activities:

But this place has done a lot for me, looking at me, looking at the things that I'm doing, the things l've been going through, and all that other mess. You kept me thinking about what's going on with me. You kept me thinking about taking my medication. Before I had gotten here to this place, I was on a sketchy I may - I get my medication, and I sell it. Okay. I may sell like three months in a row. And I ain't have no medication for the three months and didn't care. But when I turned around and came here, and then we started talking, and I started listening to what I was saying, that's the thing that's helped me a lot. Listening to what the words that were coming out of my mouth. And I did not like it. I was selfdestruct[ing], selling my meds, smoking crack, smoking so much crack that I was about ready to die. I didn't care. And through coming through here and listening to myself speak and telling you all everything that's been going on, and then how l've been doing with my medication and all this other mess, was making me look at - damn, do you want to die? Damn. You up here now with your [family]. Don't you want to see them graduate from school, high school, going on to college? I was like, yeah, I do. I really do. I'd like to see them grow up and get married. I'm only [age redacted]. I still got some time left here on this earth. As long as I take my medication. You know. As long as I take my medication, I'm good.

Thus, for William, the research project environment and specific components grounded in the ICM fostered open and honest self-reflection, and this experience of "listening to [...] the words that were coming out of my mouth" had a profound impact on his intentions regarding substance use patterns and HIV medication. Similarly, Wallace, introduced above, noted feeling committed to helping people who are suffering, but that they sometimes got in the way of "being there for myself". They described experiences in the study as a time for them to "to sit down and talk about these things out loud so that you can actually get it, process it," and "I started listening to what I was saying." These clinical experiences helped 
them to understand their own decisions and behaviors in a new and different way, which appeared to foster Wallace's more serious engagement in the behavior change process, rather than passive participation. This, thereby, helped them re-evaluate their behavior patterns (heavy substance use, selling HIV medication) and make changes:

It's one thing to just think things or hear someone else talk to you about it. But when you have a conversation about it where you're involved in the conversation or a part of the conversation, it makes a difference. You process things a little differently, and it becomes more important to you.

Further, Wallace's quote above underscores the importance of the ICM in eliciting discussion of behaviors such as heavy substance use, and selling/diverting HIV medications. These behaviors are not generally considered socially acceptable, but candid acknowledgement of and self-reflection about them are vital aspects of the behavior change process for many.

\section{Support of personal autonomy and its effects on motivation and decisions}

As described above, participants generally experienced a lack of support for their personal autonomy in health care settings, particularly with regard to HIV care and decisions related to HIV medication. In particular, participants recalled feeling unable to advocate for themselves effectively in primary medical care and other social services environments. Although participants valued their individual providers, for the most part, HIV primary care settings were described as locations where they did not feel sufficiently valued or listened to, and participants discussed feeling "stuck" and unsure if there were other options available to them; for example, regarding where else they might be able to receive care. In contrast, consistent with the ICM, participants noted the development of a sense of personal autonomy throughout their time in the Heart to Heart 2 project. Some recalled feeling unexpectedly empowered to change medical providers if they felt they were not receiving the care they needed and deserved. They also expressed renewed feelings of autonomy regarding their ability to take HIV medication regularly, remain in HIV care, and reduce substance use or substance use-related harms. Samuel, introduced above, recalled that prior to starting in the Heart to Heart 2 project they were feeling discouraged by the bureaucratic nature of the health care system, particularly at the primary care clinic they attended. They noted that experiences with the clinic, such as frustrations making appointments, made it extremely difficult to maintain their HIV care, leading them to stop caring about their health, which in turn contributed greatly to their stopping their HIV medication regimen. Samuel then described the changes they experienced in navigating their health care and HIV medication use after participating in the Heart to Heart 2 project for a year: 
Today, those same dilemmas are still there. Like, none of them have changed, but I've definitely changed a lot. You know what I'm saying? In my view of things, how I take care of myself, and how important it is to me to be medicated and stay healthy - and really almost taking my power back, my life, my control. So, it was really a big whirlwind. Even now thinking about this, like wow, honestly and truthfully somebody saved my life for $\$ 15$ [the compensation the peer received for referring him to the study].

When asked how the project helped with aspects of HIV and other health management, Samuel described the following:

Okay, well basically the whole program to me - they were never judgmental, and they never made a decision for me. They just informed me of where I was and what decisions - and began to help me put in perspective what decisions were most important to me, and how in that plan I would respond differently when faced with different dilemmas.

Samuel's experience, therefore, provides support for the importance of non-judgment and personal decision making, both of which are aspects of the ICM. Olivia, a Latinx, gay, transgender female approaching the age of 50 years, who had been living with HIV since they were a teenager, explained that they go "back and forth" with taking HIV medication regularly, since "I get tired of taking them after a while". Olivia did not start HIV medication until they were in their early 40's. They attributed this decadeslong period of not taking HIV medication to negative experiences they had in the hospital when they were first diagnosed with HIV in the early days of the epidemic, along with a general disdain for taking pills and feeling like HIV medication was a constant emotional reminder of their HIV status. In reflecting on their experiences in the study, Olivia said they felt more inclined to decide to take HIV medications as a result of their time in the study:

Because you get information from each other here and, you know, sometimes when you do better things, when you go to better places and you do better things, it makes you feel better and you want to do better. So you know what I'm saying? [...] Because you do better. Once you do better, you feel better about yourself, and that makes you want to do better. It's just like - simple. People just make it hard. Make it hard for ourselves, actually.

Marcus was a Black, gay, cisgender male in their early 50s who was diagnosed with HIV when they were a teenager. Marcus noted "the majority of people that come [to the project], they come here from SROs 
[single-room occupancy residences], from drug usage, from prostitution, from the whole low income, promiscuous lifestyle." As a result, they suggested, participants like themselves were generally reticent to speak openly with health care and social service providers about some of the more heavily stigmatized challenges they face. Marcus described their experience of being in medical environments where they felt like, "another piece of cattle just going through the chute." They described this feeling as pervasive and added that it led them to stop attending appointments with multiple providers over the years. Marcus also discussed their substance use experiences extensively and also their challenges discussing substance use with providers:

I don't talk to them [providers] about substance use. And the reason why I don't is because I believe that relapse is a part of almost everyone's story, and a doctor that tries to insert their will would be a problem for me. Because there are doctors that'll say, "Okay, you have a substance abuse problem, okay, I'm going to put all your meds in a pharmacy bottle" [so he could not sell the medications]. That's a problem because that's not me keeping myself clean. That's you trying to force me to be clean. But they'll do it. So, and that, you're not gonna make decisions for me like that in my life. A doctor that is a 100 percent abstinence doctor, I don't need them. Not saying that I do not need abstinence because I do. But that's my choice. You're not gonna take that from me. So, me being articulate and intelligent allows me to see shit that a lot of other people will take for granted. And I can hear your words, and I understand what they mean, or I understand what you're telling me by not telling me. So, I pay attention.

Marcus, therefore, highlighted the importance of autonomy support and harm reduction, both aspects of the ICM, including because a "100 percent abstinence" model is not useful to them. Similarly, Simone, introduced above, described their time in the project as valuable. Simone had a history of very difficult experiences with medical providers who Simone described as pressuring them to engage in certain health behaviors but not truly understanding their larger context or needs. According to Simone, during the project they were able to traverse through a frustrating bureaucracy and finally find a clinic where they felt comfortable and could develop a good relationship with their provider:

I mean [I was] just facing issues that you don't normally want to face. You know, things that we keep on the inside that we do have issue with going to doctors' appointments and we don't put the effort in, because of our own bias towards it. [...] But if you could just get past that, there is help. But it's a mental thing. If you have one bad experience [in HIV care], you're kind of resistive on going back again or doubtful that they're going to help you. But I don't feel like you should stop [trying]. There are hundreds of places you can go. Like just, all right, this one didn't work. Let me go here. This one didn't work. Okay, let me go here. And look, it only took me three times. Only three.... You know, so I pushed past my resistance and look, I fell into the perfect people [at an HIV care setting] for me. 
In many instances, participants emphasized that while participating in the Heart to Heart 2 project was useful, it was they themselves who carried the burden of managing HIV and they who must make the decision to take HIV medication, underscoring the importance of self-determination theory and autonomy support in the ICM. As Hank, identified above described,

I just take medication. And then here comes an oxymoron. My decision to take medication had nothing to do with you all and everything to do with you all. [...] You made me think about it. And therefore, I started taking it. But it wasn't because you all forced me to do it or anything like that. It was just you put the thought in my head. People have been doing it around me for a little while. I just needed to hear from somebody else, because I was going to go the whole holistic thing. [...] You know, herbs and all of that aromatherapy, but that shit doesn't work. Medication does.

Similarly, Samuel, described above, highlighted the utility of the ICM to guide participants toward behavior change, while supporting autonomy. Further, consistent with the ICM, which emphasizes evidence-based behavior change techniques including motivational interviewing, autonomy support alone is not generally sufficient for behavior change. Samuel said:

I was never pressured here to take medication. I was given options and choices, and discussed consequences. You know what I'm saying? Cause and effect, what this would - how this would affect me, you know what I'm saying? But never really given, you know what I'm saying, an ultimatum or this is what you need to do. You know what I'm saying? It was always all my decision, I felt. [...] I was just given the tools to make that good decision.

\section{Discussion}

The present qualitative and exploratory study focuses on a population of AABL-PLWH with socioeconomic disadvantage that experiences considerable barriers to HIV care and medication adherence, and, as a result, is either commonly not engaged, generally poorly engaged, or only intermittently engaged along the HIV care continuum. In response to the confluence of risk factors that impede HIV management in this population, and in the interest of ultimately creating new acceptable, feasible, culturally and structurally salient, and effective behavioral interventions to support sustained HIV viral suppression among AABL-PLWH, our research team developed a new ICM, which served as the foundation for clinical behavioral intervention components tested in an intervention optimization trial. Overall, results from the present study provide evidence for the ICM's important role in the acceptability and perceived utility of the study activities, and also in fostering engagement and therefore, study feasibility. Participants also reported a range of positive effects on behavior in response to the clinical 
behavioral intervention activities grounded in the ICM. In particular, the study results highlight how the ICM contributes to productive therapeutic and clinical processes between participants and interventionists, which, in turn, has potential to lead to improvements in quality of life and/or to behavior change.

\section{Trust and trustworthiness, power and privilege}

AABL-PLWH are often caught in cycles of distrust and partial self-disclosure with their health care and social service providers, in part related to pre-existing medical distrust and counter-narratives, which most care settings do not address or are not well-equipped to address [25]. Further, relationships between AABL-PLWH and providers are shaped by treatment perspectives that prioritize total abstinence from substance use, and similarly, the expectation of taking HIV medication "every dose, every day." Indeed, although harm reduction has gained some traction in HIV clinical settings, the abstinence-based perspective, applied to substance use and HIV management, has deep, historical roots [18]. These characteristics of health care settings and AABL-PLWH's perspectives on these settings certainly impede engagement along the HIV care continuum. Moreover, trust between medical or social service professional and AABL-PWLH is not easily established [76, 77]. But, trust is vital to clinical and therapeutic interactions and self-change processes and fosters openness and self-reflection, but many research and clinical settings create environments and provide services that contribute to or perpetuate distrust [78-80]. Findings from the present study suggest that aspects of the clinical behavioral intervention activities carried out in the present study increased participants' trust in the research project and study staff in many cases, although overall medical distrust and counter-narratives may have persisted. Nonetheless, AABL-PLWH can certainly engage along the HIV care continuum even while experiencing medical distrust and counter-narratives, and commonly trust their providers more than health care systems $[24,25]$.

As shown in Fig. 1, the ICM requires cultural and structural competence and comprises constructs that seek to communicate such cultural and structural competence, along with non-judgment and the support of autonomy, which in turn, is intended to foster trust between AABL-PLWH participants and the research project and its staff. Generally, we found participants engaged in frank discussions of their health decisions (e.g., not taking HIV medication) and contextual challenges (e.g., selling HIV medication, substance use) with project staff. This included participants making the decision to discuss with project staff those behaviors not typically considered socially desirable or socially acceptable. Participants contrasted their experiences in the Heart to Heart 2 project with typical health care encounters. For example, substance use and substance use problems, both past and present, are very common among AABL-PLWH, but challenging to discuss in typical health care encounters, in part due to stigma and the short interval of time patients have with providers [81]. The Heart to Heart 2 project activities grounded in the ICM, with its emphasis on non-judgement and including harm reduction, may have played a role in 
this contrast between the research project and typical care settings. Participants in the present study were from very low socio-economic status contexts, while the research study was located in a well-funded academic institution and study staff were, by and large, more privileged than participants. In such cases, power imbalances are marked and can serve as impediments to trusting relationships [82]. We speculate that the ICM approach helped project staff and participants work collaboratively across these marked differences, since the ICM explicitly recognizes participants as the ultimate experts on their health decisions. Indeed, themes related to the importance of non-judgment from project staff, a lack of pressure to take HIV medication or achieve any other specific outcome defined by the study, and the important role that open and honest communication had on self-reflection (which often spurred behavior change) were prominent in the analysis.

\section{Health care settings are heavily influenced by the larger structural and policy context}

The public health system and the individual HIV care providers within that system are charged with providing an effective and highly tolerable lifesaving treatment to individuals with a life-threatening condition, with the knowledge that such treatment can improve their wellbeing, provide them with a normal lifespan, and effectively eliminate the chances of their passing HIV [5]. Study findings suggest current medical and social service settings may not be adequately prepared to address the confluence of serious barriers that some AABL-PLWH experience to HIV care continuum engagement. Indeed, there may be frustration on both sides: AABL-PLWH express dissatisfaction with the ways they are viewed and the treatment and care they receive, including feeling pressured to take HIV medication, and HIV care settings and providers may be frustrated when patients do not take or adhere to HIV medication regimens [83]. Yet these service setting characteristics serve as direct and indirect barriers to engagement along the HIV care continuum: AABL-PLWH may avoid service settings they experience as insufficiently supportive of autonomy and that do not provide dignity-enhancing care, and, as we found in past research, these stresses, strains, insults, stigmas, and hassles are commonly internalized by AABL-PLWH over time, with grave adverse effects on one's sense of self-worth, motivation to stay healthy, and HIV management behaviors [14]. The present study highlights the need for structural changes in order to end the HIV epidemic, along with enhancements to HIV care settings consistent with the ICM, as we discuss in more detail below.

\section{Autonomy support and motivational interviewing in health care settings}

Although there are exceptions, in the present study HIV care and social service settings are generally described as dismissive of issues that AABL-PLWH commonly consider relevant to HIV management, such as poor housing quality and relationship instability, but that providers may not see as directly related to engagement along the HIV care continuum. Further, AABL-PLWH are involved in numerous institutional systems and settings that restrict their autonomy, as we describe above. Thus, AABL-PLWH 
find individualized, autonomy-supportive, and non-judgmental approaches largely lacking in the care and service settings in which they are engaged, although they tend to be satisfied with their health care providers [84]. As described above, grounded in the ICM, in the present study clinical intervention activities were guided by the motivational interviewing approach [48]. There has recently been a modest emerging literature on the use of motivational interviewing among HIV care providers. For example, Flickinger and colleagues (2013) studied motivational interviewing-consistent behavior among untrained HIV care providers. They found untrained HIV providers do not consistently use motivational interviewing techniques when counseling patients about sexual risk reduction. However, when they do, their patients are more likely to express intentions to reduce sexual risk behavior [85]. Beach and colleagues (2018) trained HIV clinicians in motivational interviewing and found improvements in overall communication measures and patient experiences [86]. Laws and colleagues (2015) caution that routine health care encounters are typically too brief for client talk to evolve toward change and health care providers are not generally trained as mental health counselors [87]. Providers with limited training may have particular difficulty maintaining motivational interviewing consistency with resistant clients.

\section{Cultural and structural salience of components}

The resonance of harm reduction and self-determination theory, aspects of the ICM, were prominent in the analysis. The role of critical race theory in the ICM were not as apparent in this analysis as aspects of the other theories or approaches, but because critical race theory was integral to the type, structure, and content of the study activities and intervention content (e.g., the role of poverty and housing, signaling the need for structural and cultural competence and salience, centering the project on AABL-PWLH), we do not consider it any less important. Indeed, throughout the project activities, participants were made aware that the Heart to Heart 2 project was focused on and interested in issues that shape the lives of AABLPLWH such as structural racism, medical distrust, and counter-narratives about the causes and treatments of HIV. Thus, we assume that we cannot interpret findings such as the resonance of the autonomy supportive approach without acknowledging the contribution of critical race theory to the ICM.

\section{Limitations}

The study has limitations including the possible influence of social desirability bias on findings. We sought to minimize social desirability bias during the interview process by asking general questions first and reminding participants they could and should feel free to decline to answer any question without penalty. The primary qualitative interviewer was not someone participants had previously met or worked with, as a further means of reducing social desirability bias. The present study does not evaluate the effectiveness of the intervention components or the most cost-effective combination of intervention components, which will be the focus of future research. Instead, we explored participants' overall 
experiences with the Heart to Heart 2 project. Further, as noted above, the acceptability, feasibility, and potential impact of the specific intervention components tested in the parent intervention optimization trial will be presented in a subsequent study, along with ways the components could be improved from the perspectives of participants. The clinical behavioral intervention components grounded in the ICM appear highly acceptable, but the Heart to Heart 2 project may have been better resourced than many HIV care settings. Indeed, the components were designed to be easy to access, flexible, and easy to navigate, but not all service settings have the resources to take such an approach. Indeed, there are disparities in funding for HIV care and social service settings, along with structural barriers such as long travel times to clinics in locations with high-HIV burdens [88, 89]. The Health Resources and Services Administration's Ryan White HIV/AIDS Program (RWHAP) has made significant progress reducing disparities in HIV care continuum engagement among populations at risk, including women, African American and Black PLWH, and unstably housed clients [90]. Yet, as described throughout the present study, gaps remain.

\section{Implications}

In Table 3 we present a number of implications for policy, health departments, and HIV care delivery models drawn from the present study. These implications fall into two main categories: implications for the larger context in which AABL-PLWH are located, including structural changes, and implications for HIV care settings. The present study indicates it will be necessary to simultaneously address structural barriers and improve HIV care delivery models to engage this subpopulation of AABL-PLWH along the care continuum consistently. For example, chronic poverty is a core cause of disengagement along HIV care continuum [91], along with poor-quality housing [92]. The present study provides insights into potential alternate approaches that can be carried out within settings. Co-located substance use and HIV services, funding for high-quality supportive housing, and collaborative patient-provider relationships could improve sustained viral suppression among populations experiencing constellations of challenges such as substance use, poverty, and long-term HIV [93]. The present study also suggests there would be utility in some cases for a comprehensive, top-to-bottom designed or re-design of HIV care delivery models, HIV care settings, and social service settings for PLWH guided by the ICM or similar model, including involving AABL-PLWH in the planning process. Fox and colleagues (2014a, 2014b) describe such a model; namely, an urban transitions clinic serving formerly incarcerated persons that evidences promising engagement and health outcomes. Yet, similar to the present study, Fox and colleagues note that that access to medical care is necessary but not sufficient to control chronic health conditions for this population with structural barriers to heath $[94,95]$. 
Table 3. Implications drawn from the present study

Implications for the larger context in which AABL-PLWH are located

It will be necessary to address structural inequality to end the HIV epidemic. Structural racism and structural inequality are fundamental causes of poor engagement along the HIV care continuum, but it is possible to address structural factors. For example, poverty is a fundamental cause of poor engagement and could be eliminated through poverty-reduction measures such as universal basic income or increasing federal financial benefit levels

In addition to addressing structural inequality, it will be necessary to tailor HIV care delivery models to the needs of AABL-PLWH to end the HIV epidemic. To bring this subpopulation of AABL-PLWH onto the HIV care continuum consistently, it will be necessary to simultaneously address structural barriers to engagement, and enhance or modify HIV care delivery models High-quality housing is a foundation of HIV management. In some geographical locations, housing support for PLWH is needed, but lacking. In other more service-rich settings, such as New York City, housing support is provided, but poor-quality housing such as single-room occupancy residences interferes with HIV care continuum engagement and wellbeing generally

Data science has a role to play in ending the HIV epidemic. AABL-PLWH tend to discontinue HIV medication when life circumstances change. Data science may play a role in efforts to predict and prevent HIV medication discontinuation along with resources (adequate financial benefits, high-quality housing) to buffer the effects of life changes

Corrupt pharmacies undermine efforts to end the HIV epidemic. Efforts to stop pharmacies from illegally buying HIV medication from patients are needed

Implications for HIV care delivery settings

Cultural and structural competence may be insufficient in many care settings. HIV care settings can be designed or re-designed to take a comprehensive, top-to-bottom approach guided by culturally and structurally competent models such as the ICM and by involving AABL-PLWH in the design process

Collaborative care approaches may be lacking in many settings. Health care providers can be 
trained in motivational interviewing and other collaborative approaches as part of a comprehensive approach to addressing the problem of poor engagement along the HIV care continuum

Health care encounters are short but barriers to engagement are serious. Since health care encounters tend to be short, health care providers can better partner with social service providers and behavioral interventionists to meet the needs to those with the greatest barriers to engagement along the HIV care continuum

PLWH not taking HIV medication often feel unwelcome in HIV care. Not all AABL-PLWH are ready to take HIV medication at any given time and those not taking medication often leave or are even pushed out of HIV primary care. Enhanced efforts to engage AABL-PLWH not taking HIV medication in HIV primary care and other services are warranted

Substance use and mental health treatment in HIV care settings may not be sufficiently available and/or effective. Substance use and substance use challenges and mental health concerns are very common among AABL-PLWH who are poorly engaged along the HIV care continuum but effective and dignity-enhancing services are lacking. Co-locating HIV care, substance use (including harm reduction approaches), mental health, navigation, and other needed services will boost engagement in these services.

Care settings may not address emotions inherent in HIV management sufficiently. Many programs and interventions for AABL-PLWH do not sufficiently attend to the emotions inherent in HIV management, but the ICM and the present study underscore the important role of emotion in engagement along the HIV care continuum

Patients and providers often have fraught relationships. Patients' relationships with providers are often complicated by fear and medical distrust, the tendency to give social desirable responses, and experiences of stigma, in the context of short health care encounter times. Approaches grounded in the ICM can foster more constructive and open communication and relationships.

Power imbalances are common between AABL-PLWH from socioeconomically disadvantaged backgrounds and providers, which may impede open and honest communication. Counseling and treatment approaches grounded in the ICM can potentially play a role in fostering open communication and trust across these imbalances. 
Individualized and flexible approaches are needed. Meeting AABL-PLWH "where they are" by addressing the health needs patients prioritize first can generate trust and foster the needed constructive provider/participant relationship, which has the potential to generate additional health goals

Disengagement from the care continuum can be prevented. Retention clinics within HIV care settings can provide targeted services to AABL-PLWH at risk for disengagement

\section{Conclusions}

Study findings indicate that the clinical intervention activities grounded in the ICM and delivered as part of the optimization trial were experienced by participants as highly acceptable, culturally and structurally salient, and useful. Further, the grounding of the study activities in the ICM contributed to participants' engagement in the study, and, therefore, to high rates of retention and study feasibility. Thus, as we hypothesized at the time the optimization trial was designed, the three theories/approaches that comprise the ICM, namely, critical race theory, harm reduction, and self-determination theory, appear to combine synergistically to create a new and useful model. The ICM may have applications for policy, to HIV care delivery models, and to other AABL populations in high-risk contexts, and warrants further study.

\section{Declarations}

\section{Acknowledgements}

The NYU Silver School of Social Work provided valuable support throughout the study. We gratefully acknowledge our Program Official at NIDA, Dr. Richard Jenkins, for guidance throughout the study, as well as Dr. Shoshana Kahana at NIDA, and Bruss Del Valle and Pauline Lee in the Office for Research at the NYU Silver School of Social Work. We wish to acknowledge Dr. Gail Melkus, Mindy Belkin, William McCormack, and Mary Lou Atkinson at the NYU Meyers College of Nursing for their support of the project. Amanda Applegate provided editorial assistance. The IIT-Lab Research Team, past and present, includes: Yvette Allen, Mariam Ayvazyan, Nico Bobb, Dr. Scott Braithwaite, Dr. Charles M. Cleland, Sabrina Cluesman, Camille Collett, Dr. Linda M. Collins, Dr. Caroline Dorsen, Brooks Fassett, Krystel Francis, Robert Freeman, Dr. Robert L. Hawkins, Ning He, Elona Hoffeld, Khadija Israel, Sarah Kaufman, Daniel Kelly, Donna Kennedy, Alexis Korman, Dr. Alix Kutnick, Dr. Noelle Leonard, Maria Levine, Belkis Y. Martinez, Dr. Michelle Munson, Sarah Ory, Shantae Owens, Emily Pan, Danny Quinones, Amanda Ritchie, Dawa Sherpa, Elizabeth Silverman, Stephen Sorgi, Aradhana Srinagesh, Karen Torbjornsen, Catherine Tumminello, Dr. Leo Wilton, and Andrea Wade. Last, we gratefully acknowledge the individuals who participated in the study. 


\section{Funding}

The study was sponsored by the National Institute on Drug Abuse (NIDA, R01DA040480) at the National Institutes of Health, and supported by the Center for Drug Use and HIV Research (CDUHR) at the NYU School of Global Public Health (P30DA011041; Holly Hagan, Ph.D., Principal Investigator).

\section{Abbreviations}

AABL $\quad$ African American/Black and Latino

CDC Centers for Disease Control and Prevention

HIV Human immunodeficiency virus

ICM Integrated conceptual model

PLWH Persons living with HIV

PTSD Post-traumatic stress disorder

REDCAP Research Electronic Data Capture

\section{Availability of data and materials}

Data are available upon reasonable request from the corresponding author.

\section{Ethics approval and consent to participate}

Procedures were approved by the Institutional Review Board at New York University Grossman School of Medicine (FWA 00004952). Participants gave signed informed consent for study activities.

\section{Competing interests}

The authors declare that they have no competing interests.

\section{Consent for publication}

Not applicable. 


\section{Authors' contributions}

MG conceptualized the purpose and design of the study, contributed to the data analysis, and wrote much of the manuscript. SRC and RF served as the primary data analysts and assisted with preparation of the manuscript. LMC, along with MG, acquired funding for the parent study and assisted with preparation of the manuscript. $C D, R L W, C M C, A S R$, and KI were engaged in the interpretive community that interpreted results and critiqued the manuscript. LW and NRL are study Co-Investigators and assisted with interpretation of findings. KT, BYM, ES, and AK designed and carried out study procedures and intervention components and critiqued the manuscript. All authors commented on previous versions of the manuscript and read and approved the final manuscript.

\section{Authors' information}

${ }^{1}$ Intervention Innovations Team Lab (IIT-Lab), New York University Silver School of Social Work, New York, NY

${ }^{2}$ Center for Drug Use and HIV Research, School of Global Public Health, New York University, New York, NY

${ }^{3}$ Independent Consultant, Brooklyn, NY

${ }^{4}$ Department of Social and Behavioral Sciences, School of Global Public Health

New York University, New York, NY

${ }^{5}$ Rutgers University School of Nursing, Newark, NJ

${ }^{6}$ Division of Biostatistics, Department of Population Health, New York University School of Medicine, New York, NY

${ }^{7}$ Department of Human Development, State University of New York at Binghamton, Binghamton, NY

${ }^{8}$ Faculty of Humanities, University of Johannesburg, Johannesburg, South Africa

${ }^{9}$ School of Global Public Health, New York University, New York, NY

${ }^{10}$ Fordham University, Department of Psychology, Bronx, NY

\section{References}

1. Gardner EM, McLees MP, Steiner JF, Del Rio C, Burman WJ. The spectrum of engagement in HIV care and its relevance to test-and-treat strategies for prevention of HIV infection. Clin Infect Dis. 
2011;52(6):793-800. DOI: 10.1093/cid/ciq243

2. The Centers of Disease Control and Prevention. HIV continuum of care, U.S., 2014, overall and by age, race/ethnicity, transmission route and sex. Available from:

https://www.cdc.gov/nchhstp/newsroom/2017/HIV-Continuum-of-Care.html. Accessed December 7, 2021.

3. Crepaz N, Dong X, Wang X, Hernandez AL, Hall HI. Racial and ethnic disparities in sustained viral suppression and transmission risk potential among persons receiving HIV care - United States, 2014. MMWR Morb Mortal Wkly Rep. 2018;64(4):113-8. DOI: 10.15585/mmwr.mm6704a2

4. Byrd KK, Hou JG, Hazen R, Kirkham H, Suzuki S, Clay PG, et al. Antiretroviral adherence level necessary for HIV viral suppression using real-world data. J Acquir Immune Defic Syndr. 2019;82(3):245-51. DOI: 10.1097/QAI.0000000000002142

5. Eisinger RW, Dieffenbach CW, Fauci AS. HIV viral load and transmissibility of HIV infection: Undetectable equals untransmittable. JAMA. 2019;321(5):451-2. DOI: 10.1001/jama.2018.21167

6. Castle B, Wendel M, Kerr J, Brooms D, Rollins A. Public health's approach to systemic racism: A systematic literature review. J Racial Ethn Health Disparities. 2019;6(1):27-36. DOI: 10.1007/s40615-018-0494-x

7. Wali N, Renzaho A, Wang X, Atkins B, Bhattacharya D. Do interventions to improve adherence to antiretroviral therapy recognise diversity? A systematic review. AIDS Care. 2020;33(11):1379-93. DOI: 10.1080/09540121.2020.1811198

8. Bradley H, Rosenberg ES, Holtgrave DR. Data-driven goals for curbing the U.S. HIV epidemic by 2030. AIDS Behav. 2019;23(3):557-63. DOI: 10.1007/s10461-019-02442-7

9. Hall HI, Brooks JT, Mermin J. Can the United States achieve 90-90-90? Curr Opin HIV AIDS. 2019;14(6):464-70. DOI: 10.1097/COH.0000000000000578

10. Eisinger RW, Fauci AS. Ending the HIV/AIDS pandemic(1). Emerg Infect Dis. 2018;24(3):413-6. DOI: 10.3201/eid2403.171797

11. Flay BR, Snyder F, Petraitis J. The theory of triadic influence. In: DiClimente RJ, Kegler MC, Crosby RA, editors. Emerging theories in health promotion practice and research. New York, NY: Jossey-Bass; 2009. p. 451-510.

12. Feagin J, Bennefield Z. Systemic racism and U.S. health care. Soc Sci Med. 2014;103:7-14. DOI: 10.1016/j.socscimed.2013.09.006

13. Kalichman SC, Kalichman MO, Cherry C. Forget about forgetting: Structural barriers and severe nonadherence to antiretroviral therapy. AIDS Care. 2017;29(4):418-22. DOI:

10.1080/09540121.2016.1220478

14. Freeman R, Gwadz M, Wilton L, Collins LM, Dorsen C, Hawkins RL, et al. Understanding long-term HIV survivorship among African American/Black and Latinx persons living with HIV in the United States: A qualitative exploration through the lens of symbolic violence. Int J Equity Health. 2020;19(1):146. DOI: 10.1186/s12939-020-01253-w 
15. Surratt HL, Kurtz SP, Cicero TJ, O'Grady C, Levi-Minzi MA. Antiretroviral medication diversion among HIV-positive substance abusers in South Florida. Am J Public Health. 2013;103(6):1026-8. DOI: 10.2105/Ajph.2012.301092

16. Dang BN, Westbrook RA, Black WC, Rodriguez-Barradas MC, Giordano TP. Examining the link between patient satisfaction and adherence to HIV care: A structural equation model. PLoS One. 2013;8(1):e54729. DOI: 10.1371/journal.pone.0054729

17. Cleland CM, Gwadz M, Collins LM, Wilton L, Sherpa D, Dorsen C, et al. African American/Black and Latino adults with detectable HIV viral load evidence substantial risk for polysubstance substance use and co-occurring problems: A latent class analysis. AIDS Behav. 2021;25(8):2501-16. DOI: 10.1007/s10461-021-03212-0

18. Szalavitz M. Undoing drugs: The untold story of harm reduction and the future of addiction. New York, NY: Hachette Go; 2021.

19. Mahajan AP, Sayles JN, Patel VA, Remien RH, Sawires SR, Ortiz DJ, et al. Stigma in the HIV/AIDS epidemic: A review of the literature and recommendations for the way forward. AIDS. 2008;22 Suppl 2(Suppl 2):S67-79. DOI: 10.1097/01.aids.0000327438.13291.62

20. Geter A, Herron AR, Sutton MY. HIV-related stigma by healthcare providers in the united states: A systematic review. AIDS Patient Care STDS. 2018;32(10):418-24. DOI: 10.1089/apc.2018.0114

21. Katz IT, Ryu AE, Onuegbu AG, Psaros C, Weiser SD, Bangsberg DR, et al. Impact of HIV-related stigma on treatment adherence: Systematic review and meta-synthesis. J Int AIDS Soc. 2013;16(3 Suppl 2):18640. DOI: 10.7448/IAS.16.3.18640

22. Earnshaw VA, Smith LR, Cunningham CO, Copenhaver MM. Intersectionality of internalized HIV stigma and internalized substance use stigma: Implications for depressive symptoms. J Health Psychol. 2015;20(8):1083-9. DOI: 10.1177/1359105313507964

23. Stockton MA, Giger K, Nyblade L. A scoping review of the role of HIV-related stigma and discrimination in noncommunicable disease care. PLoS One. 2018;13(6):e0199602. DOI: 10.1371/journal.pone.0199602

24. He N, Cleland CM, Gwadz M, Sherpa D, Ritchie AS, Martinez BY, et al. Understanding medical distrust among African American/Black and Latino persons living with HIV with sub-optimal engagement along the HIV care continuum: A machine learning approach. SAGE Open. 2021;11(4). DOI: $10.1177 / 21582440211061314$

25. Freeman R, Gwadz MV, Silverman E, Kutnick A, Leonard NR, Ritchie AS, et al. Critical race theory as a tool for understanding poor engagement along the HIV care continuum among African American/Black and Hispanic persons living with HIV in the United States: A qualitative exploration. Int J Equity Health. 2017;16(1):54. DOI: 10.1186/s12939-017-0549-3

26. Geter A, Sutton MY, Hubbard McCree D. Social and structural determinants of HIV treatment and care among Black women living with HIV infection: A systematic review: 2005-2016. AIDS Care. 2018;30(4):409-16. DOI: 10.1080/09540121.2018.1426827 
27. Gwadz M, Cleland CM, Freeman R, Wilton L, Collins LM, L. HR, et al. Stopping, starting, and sustaining HIV antiretroviral therapy: A mixed-methods exploration among African American/Black and Latino long-term survivors of HIV in an urban context. BMC Public Health. 2021;21(1):419. DOI: $10.1186 / \mathrm{s} 12889-021-10464-\mathrm{x}$

28. Carrico AW, Riley ED, Johnson MO, Charlebois ED, Neilands TB, Remien RH, et al. Psychiatric risk factors for HIV disease progression: The role of inconsistent patterns of antiretroviral therapy utilization. J Acquir Immune Defic Syndr. 2011;56(2):146-50. DOI: 10.1097/QAI.0b013e318201df63

29. Kim TW, Palepu A, Cheng DM, Libman H, Saitz R, Samet JH. Factors associated with discontinuation of antiretroviral therapy in HIV-infected patients with alcohol problems. AIDS Care. 2007;19(8):103947. DOI: $10.1080 / 09540120701294245$

30. Pellowski JA, Price DM, Harrison AD, Tuthill EL, Myer L, Operario D, et al. A systematic review and meta-analysis of antiretroviral therapy (ART) adherence interventions for women living with HIV. AIDS Behav. 2019;23(8):1998-2013. DOI: 10.1007/s10461-018-2341-9

31. Gwadz M, Cleland CM, Applegate E, Belkin M, Gandhi M, Salomon N, et al. Behavioral intervention improves treatment outcomes among HIV-infected individuals who have delayed, declined, or discontinued antiretroviral therapy: A randomized controlled trial of a novel intervention. AIDS Behav. 2015;19(10):1801-17. DOI: 10.1007/s10461-015-1054-6

32. Hartzler B, Dombrowski JC, Crane HM, Eron JJ, Geng EH, Christopher Mathews W, et al. Prevalence and predictors of substance use disorders among HIV care enrollees in the United States. AIDS Behav. 2017;21(4):1138-48. DOI: 10.1007/s10461-016-1584-6

33. Miles DRB, Bilal U, Hutton HE, Lau B, Lesko CR, Fojo A, et al. Tobacco smoking, substance use, and mental health symptoms in people with HIV in an urban HIV clinic. J Health Care Poor Underserved. 2019;30(3):1083-102. DOI: 10.1353/hpu.2019.0075

34. Mimiaga MJ, Reisner SL, Grasso C, Crane HM, Safren SA, Kitahata MM, et al. Substance use among HIV-infected patients engaged in primary care in the United States: Findings from the centers for AIDS research network of integrated clinical systems cohort. Am J Public Health. 2013;103(8):145767. DOI: 10.2105/AJPH.2012.301162

35. Gwadz MV, Collins LM, Cleland CM, Leonard NR, Wilton L, Gandhi M, et al. Using the multiphase optimization strategy (MOST) to optimize an HIV care continuum intervention for vulnerable populations: A study protocol. BMC public health. 2017;17(1):383. DOI: 10.1186/s12889-017-4279-7

36. Collins LM. Optimization of behavioral, biobehavioral, and biomedical interventions: The multiphase optimization strategy (MOST). Cham, Switzerland: Springer; 2018.

37. Delgado R, Stefanicic J. Critical race theory: An introduction. 3rd ed. New York, NY: New York University Press; 2017.

38. Harm reduction: Pragmatic strategies for managing high-risk behaviors. 2nd ed. Marlatt GA, Larimer ME, Witkiewitz K, editors. New York, NY: Guilford Press; 2012.

39. Pauly B. Harm reduction through a social justice lens. Int J Drug Policy. 2008;19(1):4-10. DOI: 10.1016/j.drugpo.2007.11.005 
40. McVinney LD. Harm reduction, crystal methamphetamine, and gay men. Harm reduction, crystal methamphetamine, and gay men. 2008;10(3-4):159-69. DOI: 10.1300/J236v10n03_15

41. Hedrich D, Hartnoll RL. Harm-reduction interventions. In: El-Guebaly N, Carrá G, Galanter M, Baldacchino AM, editors. Textbook of Addiction Treatment: International Perspectives. 2nd ed. New York, NY: Springer; 2021. p. 758-70.

42. Tatarsky A, Marlatt GA. State of the art in harm reduction psychotherapy: An emerging treatment for substance misuse. J Clin Psychol. 2010;66(2):117-22. DOI: 10.1002/jclp.20672

43. James K, Samuels I, Moran P, Stewart D. Harm reduction as a strategy for supporting people who self-harm on mental health wards: The views and experiences of practitioners. J Affect Disorders. 2017;214:67-73. DOI: 10.1016/j.jad.2017.03.002

44. Rachlis BS, Kerr T, Montaner JS, Wood E. Harm reduction in hospitals: Is it time? Harm Reduct J. 2009;6:19. DOI: 10.1186/1477-7517-6-19

45. Deci E, Ryan R. Self-determination theory. In: Van Lange PA, Kruglanski AW, Higgins ET, editors. Handbook of theories of social psychology. Thousand Oaks, CA: Sage Publications Ltd.; 2012. p. 416-36.

46. Deci EL, Ryan RM. Self-determination theory: A macrotheory of human motivation, development, and health. Can Psychol. 2008;49(3):182. DOI: 10.1037/a0012801

47. Vansteenkiste M, Williams GC, Resnicow K. Toward systematic integration between selfdetermination theory and motivational interviewing as examples of top-down and bottom-up intervention development: Autonomy or volition as a fundamental theoretical principle. Int J Behav Nutr Phys Act. 2012;9:23. DOI: 10.1186/1479-5868-9-23

48. Miller WR, Rollnick S. Motivational interviewing: Helping people change. 3rd ed. New York, NY: Guilford Press; 2012.

49. Hettema JE, Hendricks PS. Motivational interviewing for smoking cessation: A meta-analytic review. J Consult Clin Psychol. 2010;78(6):868-84. DOI: 10.1037/a0021498

50. Hill S, Kavookjian J. Motivational interviewing as a behavioral intervention to increase haart adherence in patients who are HIV-positive: A systematic review of the literature. AIDS Care. 2012;24(5):583-92. DOI: 10.1080/09540121.2011.630354

51. Armstrong MJ, Mottershead TA, Ronksley PE, Sigal RJ, Campbell TS, Hemmelgarn BR. Motivational interviewing to improve weight loss in overweight and/or obese patients: A systematic review and meta-analysis of randomised controlled trials. Obesity Rev. 2011;12(4):709-23. DOI: 10.1111/j.1467789X.2011.00892.X

52. Gwadz M, Cleland CM, Belkin M, Ritchie A, Leonard N, Riedel M, et al. Act2 peer-driven intervention increases enrollment into HIV/AIDS medical studies among African Americans/Blacks and Hispanics: A cluster randomized controlled trial. AIDS Behav. 2014;18(12):2409-22. DOI: 10.1007/s10461-014-0829-5

53. Bartholomew LK, Parcel GS, Kok G, Gottlieb NH, Schaalma H, Markham C, et al. Planning health promotion programs: An intervention mapping approach. 2nd ed. San Francisco, CA: Jossey-Bass; 
2006.

54. Metzl JM, Hansen H. Structural competency: Theorizing a new medical engagement with stigma and inequality. Soc Sci Med. 2014;103:126-33. DOI: 10.1016/j.socscimed.2013.06.032

55. Health Research \& Educational Trust. Becoming a culturally competent health care organization. Chicago, IL: American Hospital Association; 2013. Available from: https://www.aha.org/ahahretguides/2013-06-18-becoming-culturally-competent-health-care-organization. Accessed December 7, 2021.

56. Padgett DK. Qualitative methods in social work research. 3rd ed. Los Angeles, CA: Sage Publications; 2016.

57. Harris PA, Taylor R, Thielke R, Payne J, Gonzalez N, Conde JG. Research electronic data capture (REDCap)-a metadata-driven methodology and workflow process for providing translational research informatics support. J Biomed Inform. 2009;42(2):377-81. DOI: 10.1016/j.jbi.2008.08.010

58. Harris PA, Taylor R, Minor BL, Elliott V, Fernandez M, O'Neal L, et al. The REDCap consortium: Building an international community of software platform partners. J Biomed Inform. 2019;95:103208. DOI: 10.1016/j.jbi.2019.103208

59. Gwadz M, Campos S, Freeman R, Cleland CM, Wilton L, Sherpa D, et al. Black and Latino persons living with HIV evidence risk and resilience in the context of covid-19: A mixed-methods study of the early phase of the pandemic. AIDS Behav. 2021;25(5):1340-60. DOI: 10.1007/s10461-021-03177-0

60. Hsieh HF, Shannon SE. Three approaches to qualitative content analysis. Qual Health Res. 2005;15(9):1277-88. DOI: 10.1177/1049732305276687

61. Azungah T. Qualitative research: Deductive and inductive approaches to data analysis. Qual Res J. 2018;18(4):383-400. DOI: 10.1108/Qrj-D-18-00035

62. Marecek J, Fine M, Kidder L. Working between two worlds qualitative methods and psychology. In: Tolman DL, Brydon-Miller M, editors. Subjects to Subjectivities: A Handbook of Interpretive and Participatory Methods. New York, New York: New York University Press; 2001. p. 29-41.

63. Maxwell JA. Qualitative research design: An interactive approach. 3 ed. Bickman L, Rog DJ, editors. Thousand Oaks, CA: Sage Publications; 2012.

64. Bourke B. Positionality: Reflecting on the research process. Qual Rep. 2014;19(33)

65. Milner IV HR. Race, culture, and researcher positionality: Working through dangers seen, unseen, and unforeseen. Educ Res. 2007;36(7):388-400

66. Sandelowski M. Combining qualitative and quantitative sampling, data collection, and analysis techniques in mixed-method studies. Res Nurs Health. 2000;23(3):246-55. DOI: 10.1002/1098240x(200006)23:3<246::aid-nur9>3.0.co;2-h

67. Elo S, Kaariainen M, Kanste O, Polkki T, Utriainen K, Kyngas H. Qualitative content analysis: A focus on trustworthiness. Sage Open. 2014;4(1). DOI: 10.1177/2158244014522633

68. Chandler RK, Kahana SY, Fletcher B, Jones D, Finger MS, Aklin WM, et al. Data collection and harmonization in HIV research: The seek, test, treat, and retain initiative at the National Institute on 
Drug Abuse. Am J Public Health. 2015;105(12):2416-22. DOI: 10.2105/AJPH.2015.302788

69. Finkelhor D, Shattuck A, Turner H, Hamby S. A revised inventory of adverse childhood experiences. Child Abuse Negl. 2015;48:13-21. DOI: 10.1016/j.chiabu.2015.07.011

70. Hays RD, Spritzer KL, McCaffrey D, Cleary PD, Collins R, Sherbourne C, et al. The HIV cost \& services utilization study (HCSUS) measures of health-related quality of life. Santa Monica, CA: RAND; 1998.

71. WHO ASSIST Working Group. The alcohol, smoking and substance involvement screening test (ASSIST): Development, reliability and feasibility. The alcohol, smoking and substance involvement screening test (ASSIST): Development, reliability and feasibility. 2002;97(9):1183-94

72. Kroenke K, Spitzer RL, Williams JB. The PHQ-9: Validity of a brief depression severity measure. J Gen Intern Med. 2001;16(9):606-13. DOI: 10.1046/j.1525-1497.2001.016009606.x

73. Spitzer RL, Kroenke K, Williams JB, Lowe B. A brief measure for assessing generalized anxiety disorder: The GAD-7. Arch Intern Med. 2006;166(10):1092-7. DOI: 10.1001/archinte.166.10.1092

74. Prins A, Ouimette P, Kimerling R, Cameron RP, Hugelshofer DS, Shaw-Hegwer J, et al. The primary care PTSD screen (PC-PTSD): Development and operating characteristics. Primary care psychiatry. 2003;9(1):9-14. DOI: 10.1185/135525703125002360

75. Huba GJ, Melchior LA, Staff of the Measurement Group, HRSA/HAB's SPNS Cooperative Agreement Steering Committee. Module 26b: CES-D8 form. Culver City, CA: The Measurement Group; 1995. Available from: www.TheMeasurementGroup.com.

76. Dawson-Rose C, Cuca YP, Webel AR, Baez SSS, Holzemer WL, Rivero-Mendez M, et al. Building trust and relationships between patients and providers: An essential complement to health literacy in HIV care. J Assoc Nurse AIDS C. 2016;27(5):574-84. DOI: 10.1016/j.jana.2016.03.001

77. Dang BN, Westbrook RA, Njue SM, Giordano TP. Building trust and rapport early in the new doctorpatient relationship: A longitudinal qualitative study. BMC Med Educ. 2017;17(32). DOI: 10.1186/s12909-017-0868-5

78. Saha S, Jacobs EA, Moore RD, Beach MC. Trust in physicians and racial disparities in HIV care. AIDS Patient Care STDS. 2010;24(7):415-20. DOI: 10.1089/apc.2009.0288

79. Calnan M, Rowe R. Trust relations in a changing health service. J Health Serv Res Policy. 2008;13 Suppl 3:97-103. DOI: 10.1258/jhsrp.2008.008010

80. Elwyn G, Dehlendorf C, Epstein RM, Marrin K, White J, Frosch DL. Shared decision making and motivational interviewing: Achieving patient-centered care across the spectrum of health care problems. Ann Fam Med. 2014;12(3):270-5. DOI: 10.1370/afm.1615

81. Gwadz M, de Guzman R, Freeman R, Kutnick A, Silverman E, Leonard NR, et al. Exploring how substance use impedes engagement along the HIV care continuum: A qualitative study. Front Public Health. 2016;4:62. DOI: 10.3389/fpubh.2016.00062

82. Laugharne R, Priebe S. Trust, choice and power in mental health: A literature review. Soc Psychiatry Psychiatr Epidemiol. 2006;41(11):843-52. DOI: 10.1007/s00127-006-0123-6 
83. Gwadz MV, Cleland C, Martinez B, Ritchie AS, Freeman R, Leonard NR, et al. Frustrated patients, frustrated providers: A comprehensive integrated conceptual model to explain why patients delay, decline, or discontinue HIV medication, and strategies to boost sustainted HIV viral suppression in populations at-risk. Paper presented at: 10th IAS Conference on HIV Science; 2019 July 21-24; Mexico City, Mexico.

84. Oetzel J, Wilcox B, Avila M, Hill R, Archiopoli A, Ginossar T. Patient-provider interaction, patient satisfaction, and health outcomes: Testing explanatory models for people living with HIV/AIDS. AIDS Care. 2015;27(8):972-8. DOI: 10.1080/09540121.2015.1015478

85. Flickinger TE, Rose G, Wilson IB, Wolfe H, Saha S, Korthuis PT, et al. Motivational interviewing by HIV care providers is associated with patient intentions to reduce unsafe sexual behavior. Patient Educ Couns. 2013;93(1):122-9. DOI: 10.1016/j.pec.2013.04.001

86. Beach MC, Laws MB, Rose G, Roter D, Lee Y, Chander G, et al. Effects of minimal versus intensive intervention to enhance motivational interviewing in HIV care. AIDS Behav. 2018;22(1):276-86. DOI: 10.1007/s10461-017-1794-6

87. Laws MB, Rose GS, Beach MC, Lee Y, Rogers WS, Velasco AB, et al. Patient-provider concordance with behavioral change goals drives measures of motivational interviewing consistency. Patient Educ Couns. 2015;98(6):728-33. DOI: 10.1016/j.pec.2015.02.014

88. Kimmel AD, Martin EG, Galadima H, Bono RS, Tehrani AB, Cyrus JW, et al. Clinical outcomes of HIV care delivery models in the us: A systematic review. Clinical outcomes of HIV care delivery models in the us: A systematic review. 2016;28(10):1215-22. DOI: 10.1080/09540121.2016.1178702

89. Kimmel AD, Masiano SP, Bono RS, Martin EG, Belgrave FZ, Adimora AA, et al. Structural barriers to comprehensive, coordinated HIV care: Geographic accessibility in the US South. AIDS Care. 2018;30(11):1459-68. DOI: 10.1080/09540121.2018.1476656

90. Mandsager P, Marier A, Cohen S, Fanning M, Hauck H, Cheever LW. Reducing HIV-related health disparities in the health resources and services administration's Ryan White HIV/AIDS program. Am J Public Health. 2018;108(S4):S246-S50. DOI: 10.2105/AJPH.2018.304689

91. Eberhart MG, Yehia BR, Hillier A, Voytek CD, Fiore DJ, Blank M, et al. Individual and community factors associated with geographic clusters of poor HIV care retention and poor viral suppression. $J$ Acquir Immune Defic Syndr. 2015;69 Suppl 1:S37-43. DOI: 10.1097/QAI.0000000000000587

92. Lekas HM, Lewis C, Lunden S, Olender SA, Rosen-Metsch L. Single room occupancy residence: Processes linking housing to not engaging in HIV outpatient care. AIDS Behav. 2021;25(8):2644-56. DOI: $10.1007 / \mathrm{s} 10461-021-03225-9$

93. Paschen-Wolff MM, Campbell ANC, Tross S, Choo TH, Pavlicova M, Braunstein S, et al. Durable viral suppression among people with HIV and problem substance use in the era of universal antiretroviral treatment. AIDS Behav. 2021. DOI: 10.1007/s10461-021-03392-9

94. Fox AD, Anderson MR, Bartlett G, Valverde J, Starrels JL, Cunningham CO. Health outcomes and retention in care following release from prison for patients of an urban post-incarceration transitions clinic. J Health Care Poor Underserved. 2014;25(3):1139-52. DOI: 10.1353/hpu.2014.0139 
95. Fox AD, Anderson MR, Bartlett G, Valverde J, MacDonald RF, Shapiro LI, et al. A description of an urban transitions clinic serving formerly incarcerated people. J Health Care Poor Underserved. 2014;25(1):376-82. DOI: 10.1353/hpu.2014.0039

\section{Figures}

Fig. 1. Depiction of the integrated conceptual model that resulted from the combination of critical race theory, harm reduction, and self-determination theory

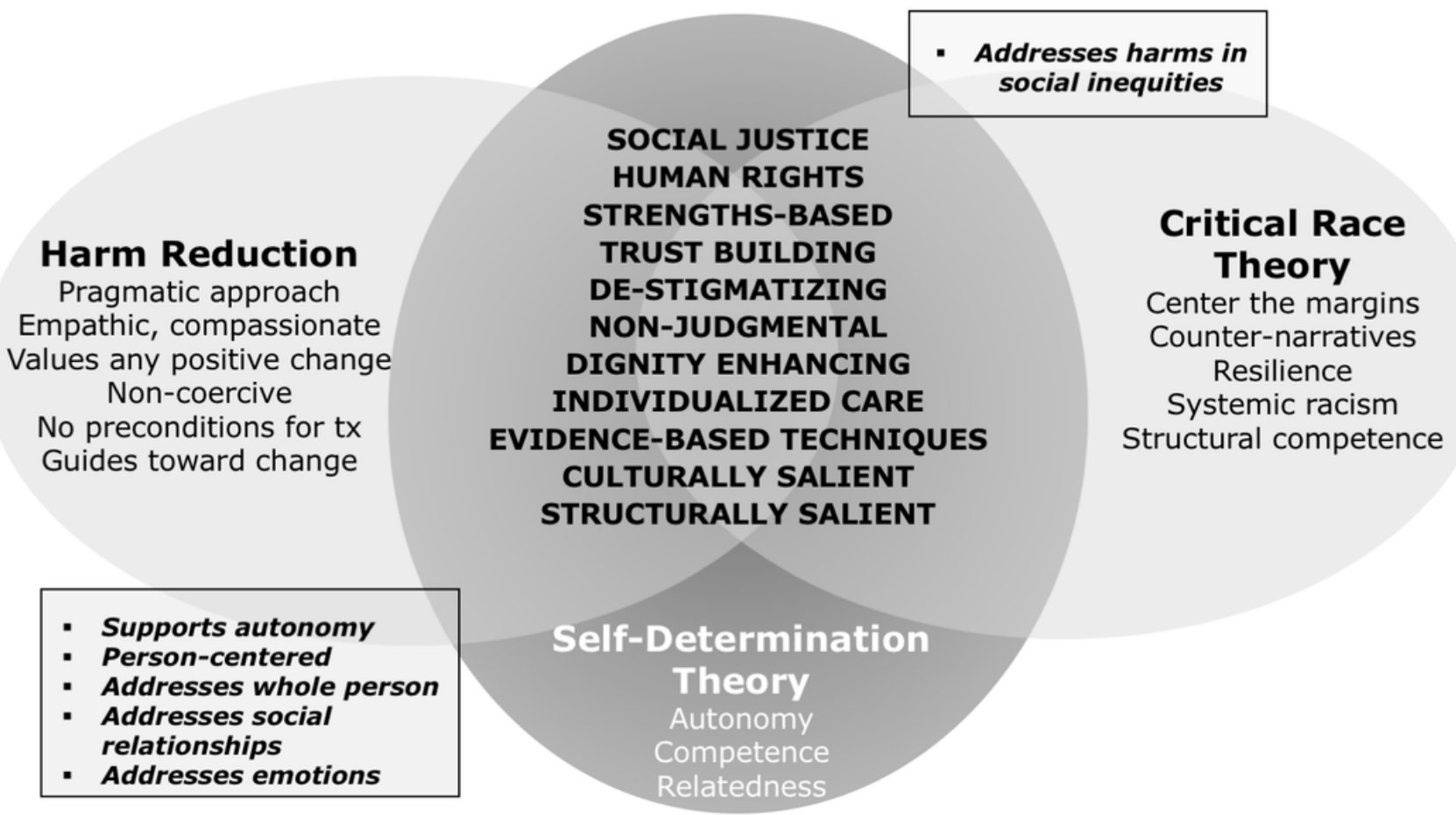

Figure 1

Depiction of the integrated conceptual model that resulted from the combination of critical race theory, harm reduction, and self-determination theory 